\title{
Reversible phosphorylation of the 26S proteasome
}

\author{
Xing Guo ${ }^{1 \bowtie}$ (D) Xiuliang Huang ${ }^{2}$, Mark J. Chen ${ }^{3}$ \\ 1 The Life Sciences Institute of Zhejiang University, Hangzhou 310058, China \\ 2 Ministry of Education Key Laboratory of Protein Science, School of Life Sciences, Tsinghua University, Beijing 100084, China \\ ${ }^{3}$ Department of Bioinformatics and Computational Biology, Genentech Inc., South San Francisco, CA 94080, USA \\ $\triangle$ Correspondence: xguo@zju.edu.cn (X. Guo)
}

Received December 15, 2016 Accepted January 26, 2017

\begin{abstract}
The $26 \mathrm{~S}$ proteasome at the center of the ubiquitinproteasome system (UPS) is essential for virtually all cellular processes of eukaryotes. A common misconception about the proteasome is that, once made, it remains as a static and uniform complex with spontaneous and constitutive activity for protein degradation. Recent discoveries have provided compelling evidence to support the exact opposite insomuch as the $26 \mathrm{~S}$ proteasome undergoes dynamic and reversible phosphorylation under a variety of physiopathological conditions. In this review, we summarize the history and current understanding of proteasome phosphorylation, and advocate the idea of targeting proteasome kinases/ phosphatases as a new strategy for clinical interventions of several human diseases.
\end{abstract}

KEYWORDS proteasome, phosphorylation, kinase, phosphatase, protein degradation

\section{INTRODUCTION}

The year of 2017 marks the 30th anniversary of the discovery of proteasome, the central hub of protein degradation in all eukaryotic cells (Hough et al., 1987; Waxman et al., 1987). The past three decades have witnessed enormous advancement of our understanding about proteasomal degradation of proteins involved in almost every aspect of cell biology. The biological importance, biochemical complexity, and clinical relevance of the proteasome system are

Electronic supplementary material The online version of this article (doi:10.1007/s13238-017-0382-x) contains supplementary material, which is available to authorized users. now well established, although many important details of proteasome function, structure, and regulation remain elusive and will continue to be topics of intensive research (Finley, 2009; Schmidt and Finley, 2014; Finley et al., 2016; Livneh et al., 2016).

The core of all proteasome complexes is a 28-subunit, barrel-shaped structure known as the $20 \mathrm{~S}$ proteasome or core particle (20S CP). These subunits are arranged as four stacked rings (Groll et al., 1997; Unno et al., 2002). The two outer rings (at the top and bottom of the CP) are made of $\alpha$ subunits ( $\alpha 1-7$, designated PSMAs in human and higher eukaryotes), whose $\mathrm{N}$-termini form a "gate" at the axial center and occlude the entrance into the $\mathrm{CP}$ chamber. Each of the two inner rings is composed of subunits $\beta 1-7$ (PSMBs). Three of the $\beta$ subunits, namely $\beta 1, \beta 2$ and $\beta 5$, function as threonine-proteases and preferentially cleave substrate polypepetides after acidic (caspase-like activity), basic (trypsin-like activity), and hydrophobic residues (chymotrypsin-like activity), respectively. All their $\mathrm{N}$-terminal active sites are positioned at the interior center of the CP. In addition to these constitutive subunits, the $\mathrm{CP}$ can incorporate specialized subunits such as $\beta 1 \mathrm{i}, \beta 2 \mathrm{i}$, and $\beta 5 \mathrm{i}$ to form immunoproteasomes (Kloetzel, 2001), or $\beta 5$ t to form thymoproteasomes (Murata et al., 2007), or $\alpha 4$ s instead of $\alpha 4$ in the testis (Uechi et al., 2014). Due to its unique architecture, the 20S proteasome in its free form cannot degrade folded protein substrates as they are inaccessible to the catalytic center.

For proteasomal degradation to occur, the gate formed by a subunits must be opened to allow for substrate entry. This "gate-opening" function can be achieved by several types of proteasome activators that directly bind the $\alpha$ ring, including the 19S regulatory particle (RP)/PA700, 11S/PA28/REG, and BIm10/PA200 (Stadtmueller and Hill, 2011). Thus, different forms of $\mathrm{CP}$ may associate with different activators, resulting 
in multiple types of proteasome complexes that co-exist in cells. The 19S RP has been widely studied and together with 20S CP forms the best known 26S proteasome, a 2.0-2.5 $\mathrm{MDa}$ machinery that degrades the vast majority of polyubiquitinated as well as some non-ubiquitinated proteins of the cell (Finley, 2009).

A total of nineteen subunits assemble into the 19S RP, including six AAA+ type ATPases (Rpt1-6, or PSMCs) and thirteen non-ATPase proteins (Rpn1-3, 5-13 and 15, known as PSMDs). Each Rpt subunit contains an $\mathrm{N}$-terminal flexible region, a coiled-coil domain, an oligonucleotide-binding (OB) domain and an ATPase domain. The coiled-coil regions are required for dimerization of Rpt1-Rpt2, Rpt3-Rpt6, and Rpt4Rpt5, which join with one another in the presence of multiple assembly chaperones to form a hexameric ATPase ring that directly caps one or both ends of the CP (Funakoshi et al., 2009; Kaneko et al., 2009; Murata et al., 2009; Park et al., 2009; Roelofs et al., 2009; Yu et al., 2010). In the Rpt ring structure, the OB and ATPase domains make up the central channel, which upon substrate polypeptide binding aligns with the CP gate to form a continuous passage. Substrate engagement with Rpts also stimulates their ATPase activity that in turn provides the necessary energy for substrate unfolding before its translocation to the CP (Smith et al., 2005; Peth et al., 2013). The extreme C-termini of Rpt2, 3, and 5 contain a $\mathrm{HbYX}$ motif (hydrophobic residue-tyrosineany amino acid). They play critical roles in RP-CP interaction by directly inserting into pockets of the $\alpha$ ring, at the same time causing significant conformational changes and opening of the CP gate (Smith et al., 2007; Rabl et al., 2008; Park et al., 2009). The coiled-coil, OB, ATPase domains and the $\mathrm{HbYX}$ motif are well defined in crystal and cryo-EM structures, and their primary sequences are highly conserved through evolution (Djuranovic et al., 2009; Chen et al., 2016; Huang et al., 2016; Schweitzer et al., 2016). On the other hand, the extreme $\mathrm{N}$-termini of Rpts appear to be poorly structured and less conserved, although they harbor modification sites that are important for modulating proteasome functions (See later).

Rpt1-6 and three non-ATPase subunits (Rpn1, 2, and 13) are traditionally referred to as the "base" of the 19S RP, while the remaining Rpn subunits constitute the "lid". In the cyroEM models, Rpn2 is positioned at the apex of the 26S holoenzyme (farthest from the 20S CP) and directly contacts the coiled-coils of Rpt3-Rpt6. The latter serves as a pivot around which the lid complex rotates in accord with substrate engagement, unfolding, and translocation (Matyskiela et al., 2013; Unverdorben et al., 2014). Rpn1, Rpn10, and Rpn13 function as receptors for ubiquitin and ubiquitin-like (UBL) domain proteins (Deveraux et al., 1995; Husnjak et al., 2008; Schreiner et al., 2008; Shi et al., 2016). The proteasomeintrinsic de-ubiquitinating enzyme Rpn11 and its partner Rpn8 cleave off ubiquitin chains from committed protein substrates in order to facilitate substrate unfolding, translocation, and ubiquitin recycling (Verma et al., 2002; Yao and Cohen, 2002; Worden et al., 2014). The rest of RP subunits
(Rpn3, 5, 6, 7, 9, 12, 15) are not known to possess enzymatic or receptor properties but play essential structural functions in $26 \mathrm{~S}$ proteasome assembly. Working as a complex, the 19S RP is responsible for (i) substrate recognition and engagement, (ii) substrate de-ubiquitination, (iii) substrate unfolding and translocation, and (iv) 205 gate opening and activation. Of note, all these activities except for substrate recognition depend on ATP binding/hydrolysis by the ATPase subunits. Therefore, Rpt1-6 play structural, enzymatic, and regulatory roles that are essential for $26 \mathrm{~S}$ proteasome function (Finley, 2009; Ehlinger and Walters, 2013).

The assembly of individual subunits into a functional proteasome is controlled by a series of chaperone proteins, representing the best characterized aspect of proteasome regulation (Murata et al., 2009). Most chaperones are absent/dislodged from the fully assembled complex, while dozens to hundreds of other cellular proteins can dynamically interact with the mature proteasome (Wang et al., 2007; Wang and Huang, 2008). Although the biological meanings of these interactions are largely unknown, many proteasome-interacting proteins (PIPs) have enzymatic activities and modify the proteasome in a variety of ways (reviewed by Scruggs et al., 2012; Cui et al., 2014). Not surprisingly, phosphorylation is one of the most frequent and better studied means of post-translational modification of the proteasome.

In this review, we summarize our current understanding of proteasome regulation by reversible phosphorylation. Due to space limit, we only focus on phosphorylations of integral subunits of the constitutive human $26 \mathrm{~S}$ proteasome (We will adhere to the nomenclature of $\alpha 1-7, \beta 1-7$, Rpt1-6, and Rpns to avoid confusion) and highlight the functions of selected kinases/phosphatases and phosphosites (Fig. 1). We also discuss technical issues and potential clinical applications of present research on proteasome phosphoregulation.

\section{OVERVIEW OF 26S PROTEASOME PHOSPHORYLATION}

The first documentation of proteasome phosphorylation dates back to 1989 , not long after the discovery of the proteasome itself, when Haass and Kloetzel reported that proteasome subunits were modified (phosphorylated) in Drosophila cells. These researchers insightfully argued that "the in vivo proteolytic activity and the in vivo substrate specificity of the proteasome may be regulated by modification of its subunit composition during fly development" (Haass and Kloetzel, 1989). Their observations have now been supported by finer proteomic studies of many organisms, and yet the biological significance of proteasome phosphorylation during development is, by and large, still a mystery.

In the following decade, numerous independent reports had demonstrated phosphorylations of different proteasome subunits with limited information on their function. 


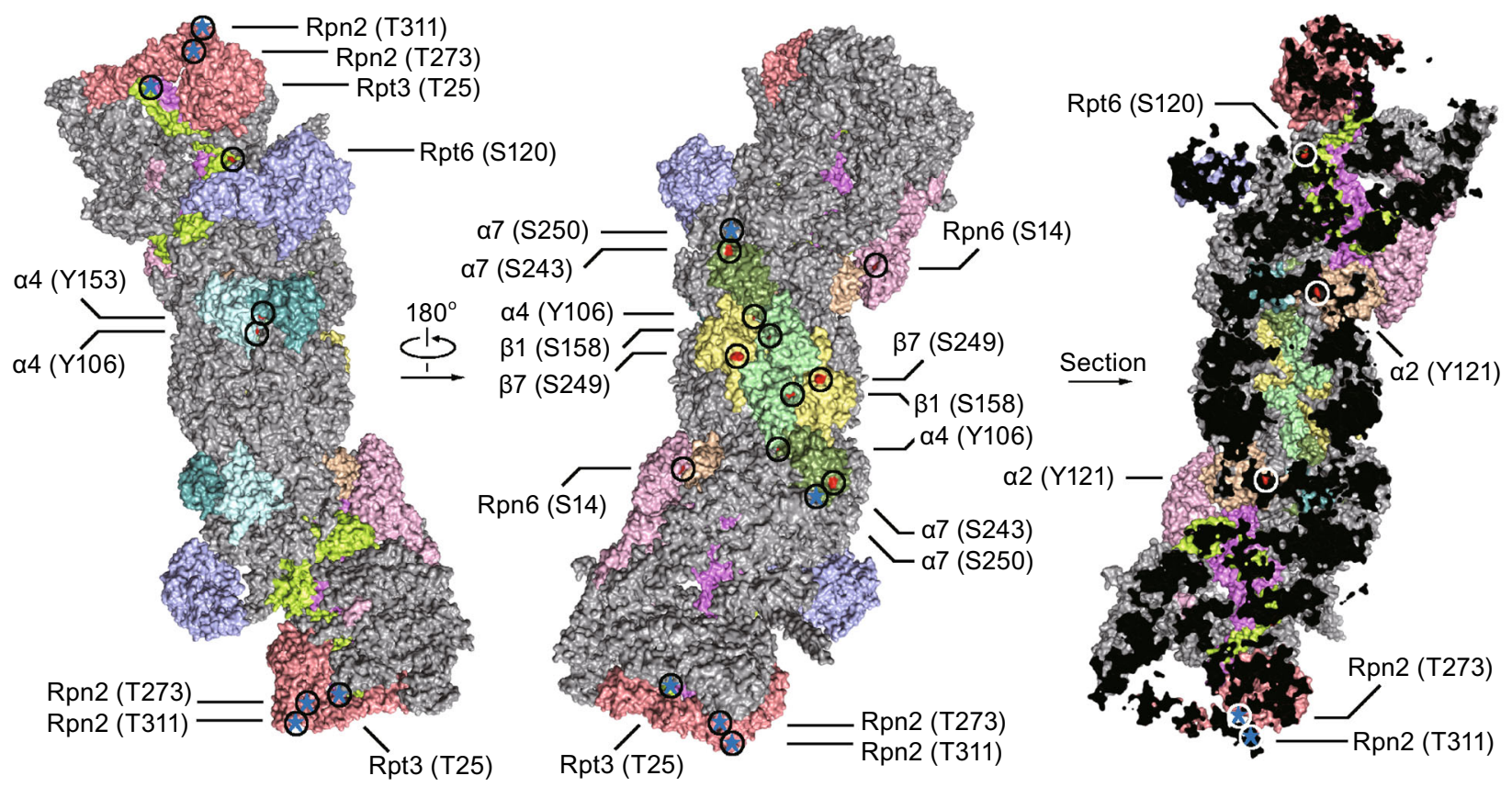

Figure 1. Structural view of a selection of human $26 \mathrm{~S}$ proteasome phosphosites. Surface (left, middle) and sectional (right) views of human 26S proteasome (gray) are shown based on high-resolution cryo-EM structures (PDB 5GJR). Phosphosites of subunits Rpt6 (lemon), Rpn6 (light pink), $\alpha 7$ (smudge), Rpt3 (violet), Rpn2 (salmon), a4 (pale cyan), $\alpha 2$ (wheat), $\beta 7$ (pale yellow), $\beta 1$ (pale green) are marked with circles. Sites visible from available structures are highlighted in red, while predicted positions of invisible sites are represented with a blue star.

Phosphorylation was even once considered to partly account for the ATP-dependence of proteasome function (Ludemann et al., 1993). Some of the early studies reached inconsistent and occasionally contradictory conclusions as to which subunits were phosphorylated on which sites, largely due to differences among cell types (with distinct expression and activity of kinases/phosphatases), species (with or without a non-conserved phosphosite), and purification procedures (Labile phosphorylations are easily lost during lengthy chromatography or in the absence of phosphatase inhibitors). Moreover, it was very difficult, if not entirely impossible, to determine the exact phosphorylation sites of a gigantic protein complex like the proteasome simply by ${ }^{32} \mathrm{P}$ labeling, 2D-electrophoresis, and phosphoamino acid mapping. In fact, phosphorylations detected by these methods were either highly abundant in a particular cell/tissue type, or fairly resistant to dephosphorylation, or possibly artifacts of proteasome purification and in vitro kinase reactions.

The advent of tandem mass spectrometry (MS/MS)based phosphoproteomics caused revolutionary changes in our understanding of proteasome regulation. Less than a dozen phosphosites were known to exist on human $26 \mathrm{~S}$ proteasome by the early 2000's, while the number rocketed to over 300 by 2013 according to PhosphoSitePlus, one of the most comprehensive phosphoproteomic databases (www.phosphosite.org). The current tally (by July, 2016) is 455 phosphosites. These include 201 phospho-serine (pS) sites, 104 phospho-threonine (pT) sites, and 150 phosphotyrosine $(\mathrm{pY})$ sites, all but two of which have been detected by large-scale MS studies. A complete list of all human proteasome phosphosites is available in Table S1. In the following discussions, we will primarily rely on information from PhosphoSitePlus, and refer to the PhosphoGrid (phosphogrid.org) and PhosphoMouse (https://gygi.med. harvard.edu/phosphomouse/) databases for phosphorylations of yeast and mouse proteasomes, respectively.

Proteasome phosphorylations are seen in almost every large-scale phosphoproteomic dataset. More importantly, the proteasome is dynamically phosphorylated in a variety of physiological and pathological processes, including development and stem/progenitor cell differentiation (Brill et al., 2009; Rigbolt et al., 2011; Goswami et al., 2012), cell cycle (Beausoleil et al., 2006; Dephoure et al., 2008; Nagano et al., 2009; Olsen et al., 2010; Kettenbach et al., 2011; Guo et al., 2016), DNA damage response (Matsuoka et al., 2007; Stokes et al., 2007), stress responses (Um et al., 2010; Wang et al., 2014), immune signaling (Bose et al., 2001; Bose et al., 2004; Mayya et al., 2009; Weintz et al., 2010; Wu et al., 2012), metabolic changes (Bardag-Gorce et al., 2004; Zhang et al., 2007b; Trost et al., 2012), neuronal activity (Djakovic et al., 2009; Bingol et al., 2010; Djakovic et al., 
2012; Hamilton et al., 2012; Jarome et al., 2013; Jarome et al., 2016; Li et al., 2016), hormones and growth factor signaling (Kim et al., 2009; Pan et al., 2009; Lundby et al., 2013; Williams et al., 2016), and oncogenesis (Rush et al., 2005; Rikova et al., 2007; Guo et al., 2008; Luo et al., 2008; Choudhary et al., 2009; Eang et al., 2009; Iliuk et al., 2010; Johnson et al., 2012; Trost et al., 2012; Yuan et al., 2013). Although the functional roles of proteasome phosphorylation in these processes are largely uncharacterized, increasing evidence indicates that the $26 \mathrm{~S}$ proteasome is not a uniform and static complex acting passively as a "cellular trashcan". Rather, the proteasome itself is fine-tuned by reversible phosphorylation in response to intra- and extra-cellular signals, which can be a prerequisite or feedback mechanism for a wide spectrum of cellular events that depend on proteasome function.

A quick examination of the human proteasome phosphorylation data shows that phosphosites have been found on every subunit. The largest subunit Rpn2 has the most phosphorylation sites (27) while the smallest subunit Rpn15 has only one. However, no correlation exists between the number of phosphosites and the size of protein for most of the subunits. Overall, it appears that the 20S CP and the 19S base subunits are more frequently phosphorylated than the $19 S$ lid, when the total number of MS detections for each site (based on the high-throughput, i.e. "HTP" numbers from PhosphoSitePlus) is taken into account. It should be noted, though, that more than half of the proteasome phosphorylations were detected only once by MS, and only $20 \%$ of all human proteasome phosphosites were observed for more than 5 times in all the studies combined. On the other hand, the frequency of MS detection of a proteasome phosphosite does not directly translate into its stoichiometry or functional importance, due to vastly different sample sources, purification/enrichment methods, detection instruments, and search databases used by various groups. As illustrated later in detail, some of the functionally important phosphosites have only been observed in a temporally or spatially restricted manner, demonstrating the intricate nature of proteasome phosphoregulation.

Of the 455 known phosphosites on human $26 \mathrm{~S}$ proteasome, $442(97.1 \%)$ are conserved or semi-conserved (i.e. Ser/Thr substitutions) in mouse and rat proteasome subunits, and 391 sites (85.9\% of total) are found in zebrafish. However, the degree of site conservation drops considerably to $63.3 \%$ in fruit fly (D. melanogaster) and less than $50 \%$ in worm (C. elegans) and yeast ( $S$. cerevisiae). Yeast $26 S$ proteasome has been shown to be phosphorylated at low stoichiometry (Wu et al., 2011). The majority of yeast proteasome phosphorylation sites (Kikuchi et al., 2010), if conserved, are rarely phosphorylated in mammals. These observations suggest that novel phosphosites emerged during evolution (especially in vertebrates) as new regulatory mechanisms of proteasome function, a general theme that has been proposed for phospho-signaling (Holt et al., 2009).
The surrounding sequences of many proteasome phosphosites conform to well defined recognition motifs of kinases, such as S/TP (MAPKs and CDKs), R/KxxS/T (AGC and CaMK families), S/TxxD/E (CK1 and CK2), and S/TxxxS/T (GSK3). Some of the most frequent motifs found on the proteasome are summarized in Figs. 2 and S1. Even with this information, it is generally a challenging task to pinpoint the kinase(s) for a given site, which has been a major hurdle toward understanding the regulation and function of proteasome phosphorylation. Up next, we will focus on functionally characterized proteasome kinases and phosphatases to showcase the biological relevance of proteasome phosphorylation.

\section{PROTEASOME KINASES AND PHOSPHATASES}

\section{PKA}

Protein kinase A (PKA) was probably the first kinase implicated in proteasome phosphorylation. The initial hint was copurification of a cAMP-dependent kinase activity with the proteasome complex from bovine pituitaries. This putative kinase reportedly phosphorylated two proteins of $27-28 \mathrm{kDa}$, likely to be $20 S$ subunits (Pereira and Wilk, 1990). Supporting the involvement of PKA in proteasome regulation, Marambaud et al. showed that the common activator of PKA, forskolin, stimulated endogenous proteasome activity in HEK293 cells. Purified PKA phosphorylated some 28-30 $\mathrm{kDa}$ subunits in vitro, leading to evident upregulation of peptidase activity (Marambaud et al., 1996). These original findings have been substantiated by subsequent studies. In particular, endogenous $20 \mathrm{~S}$ proteasomes isolated from murine hearts also contains PKA a (catalytic) subunit as confirmed by Western blot and MS, and PKA-mediated in vitro phosphorylation enhances peptidase activities of $20 \mathrm{~S}$ proteasomes isolated from both heart and liver (Zong et al., 2006; Lu et al., 2008). Interestingly, Zong et al. also indicated the presence of phosphatase PP2A (including its $\alpha, \beta$, and $\gamma$ subunits) in cardiac $20 S$ complexes, and inhibition of PP2A by okadaic acid (OA) increased proteasome activity. These data demonstrate that phosphorylation by PKA positively regulates the $20 \mathrm{~S}$ proteasome.

However, when incubated with purified intact 26S proteasome in vitro, PKA preferentially phosphorylates certain $19 S$ subunit(s) instead of the 20 S component (Zhang et al., 2007a and our unpublished observation). Just like the $20 S$ $\mathrm{CP}$, the 26S holoenzyme becomes more active upon PKAmediated phosphorylation, an effect that can be reversed by the phosphatase PP1y (Zhang et al., 2007a). MS analysis showed that recombinant PKA directly phosphorylates Rpt6 at Ser120 in vitro, while the Ser120Ala mutation blocks this phosphorylation and significantly reduces proteasome activity in cells (Zhang et al., 2007a). Echoing these results, Lin et al. reported that disease-causing mutants of Huntingtin (mHTT) could reduce overall PKA activity, Rpt6-S120 phosphorylation hence proteasome activity, causing a 

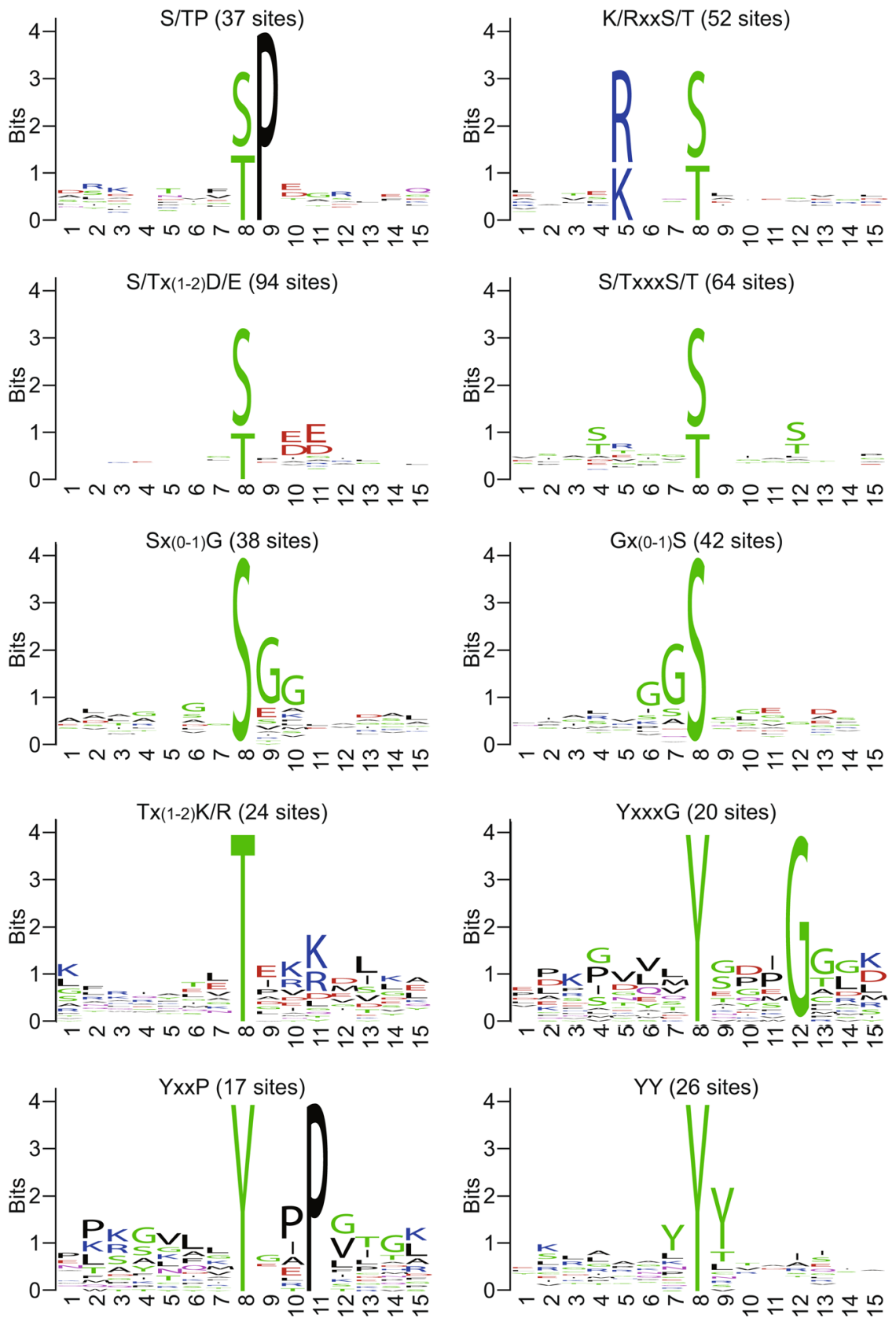

Figure 2. Representative sequence motifs of human proteasome phosphosites. All human proteasome phosphorylation sites were divided into pS, pT, and pY groups and their adjacent sequences were separately analysed with Motif-All. Similar motifs were combined and sequence logos of the ten most abundant representatives are shown. The $\mathrm{X}$-axis shows amino acid positions with the phosphosites in the center. The Y-axis is the information content, which takes into account the frequency of amino acid across the proteome (background frequency) and is therefore a better measure.

positive feedback leading to $\mathrm{mHTT}$ accumulation (Lin et al., 2013).

Rpt6-S120 is conserved from yeast to human and is arguably the best characterized among all proteasome phosphorylation sites, and yet several studies have convincingly demonstrated that it is in fact targeted by a different kinase, CaMKIla (See later for details). Moreover, two groups have directly challenged PKA as the true Rpt6-S120 kinase (Jarome et al., 2013; Lokireddy et al., 2015). In fact, Ser120 of Rpt6 is preceded by an arginine residue at the -3 position $\left(R_{117} N D S_{120}\right)$, which constitutes a typical $R X X S / T$ recognition motif shared by AGC kinases (such as PKA) and CaMKs (such as CaMKIla). It is possible that PKA phosphorylates Ser120 in vitro but not necessarily in vivo. In 
addition, detection of phospho-S120 with a phospho-specific antibody against PKA substrates (recognizing the RXXpS/T motif, Lin et al., 2013) does not establish PKA as the kinase. Moreover, PKA promotes the association between 19S and 20 proteasomes (See below), while $\mathrm{S} 120$ phosphorylation by CaMKIla was shown not to affect proteasome assembly (Djakovic et al., 2009). Finally, in contrast to the wide distribution of PKA in many cell types, detection of endogenous Rpt6-S120 phosphorylation has primarily been restricted to neuronal cells, where CaMKIla is highly enriched. Therefore, it remains to be determined whether PKA phosphorylates Rpt6-S120 in vivo at all, or if so, under what circumstances.

Nonetheless, PKA-mediated 26S proteasome activation and the ensuing beneficial effects on protecting neuronal cells from toxic protein aggregates have been established (Myeku et al., 2012; Lokireddy et al., 2015; Myeku et al., 2016). cAMP signal not only activates PKA but also increases the association between its catalytic subunit and the proteasome. This leads to phosphorylation of Rpn6 (but not Rpt6) at Ser14, shown by Phos-tag SDS/PAGE and confirmed by MS. Rpn6-S14 phosphorylation enhances proteasome ATPase activity and promotes the formation of doubly capped (30S) proteasome, hence accelerating the degradation of short-lived proteins (Table 1). The phosphomimetic mutant Rpn6-S14D facilitates the clearance of a variety of aggregation-prone proteins closely associated with neurological diseases, while the phospho-deficient mutant Rpn6-S14A does the opposite (Lokireddy et al., 2015). Importantly, the effect of PKA activation on proteasome assembly occurs in vivo (Asai et al., 2009; Myeku et al., 2016). The latter study showed that rolipram (a specific phosphodiesterase type 4 inhibitor and PKA stimulator) activates proteasome in mouse brain and prevents proteasome impairment by mutant tau at the early stage of tauopathy, leading to improved cognitive ability (Myeku et al., 2016). More recently, researchers have demonstrated that many hormones (e.g. epinephrine and glucagon) and physiological responses (such as exercise or fasting) that increase cAMP levels also activate the proteasomes and stimulate Rpn6-S14 phosphorylation as shown with a phospho-specific antibody (personal communication with A. L. Goldberg). These findings are of obvious clinical relevance and suggest new approaches to (re)activate the proteasome and halt neurodegeneration. However, cautions should be taken because Rpn6-S14 phosphorylation also appears to be upregulated in cancer cells (Gnad et al., 2013; Mertins et al., 2014) and during T cell activation (Ruperez et al., 2012), the consequences of which have not been investigated.

\section{CK2}

Similar to PKA, protein kinase CK2 has a ubiquitous expression profile among tissues and cell types, and is one of the first kinases reported to co-purify with the proteasome from mammalian sources and phosphorylate distinct $\alpha$ subunits (Ludemann et al., 1993; Castano et al., 1996; Mason et al., 1996). Interestingly, CK2 orthologs were shown to phosphorylate 20S subunits of fungi and plants (Umeda et al., 1997; Pardo et al., 1998; Murray et al., 2002), suggesting that this may be a conserved and common property of CK2.

In search for a kinase activity that associates with the $20 \mathrm{~S}$ proteasome from human erythrocytes, Ludemann et al. found that the putative kinase was distinct from PKA (the only known proteasome kinase then) in that it was insensitive to cAMP but could be effectively blocked by heparin, an inhibitor of CK2. Western blot analysis confirmed the presence of CK2 in $20 \mathrm{~S}$ proteasome preparations, and in vitro phosphorylation of a specific $30 \mathrm{kDa}$ subunit could be eliminated by immunodepletion of CK2 from the proteasome sample. However, CK2 phosphorylation did not seem to affect 20 S proteasome activity (Ludemann et al., 1993). A few years later, two groups independently reported that two $\alpha$ subunits, $\alpha 7 / \mathrm{PSMA} 3 / \mathrm{C} 8$ and $\alpha 3 / \mathrm{PSMA} 4 / \mathrm{C} 9$, were predominantly phosphorylated in cells labeled with ${ }^{32} \mathrm{P}$-orthophosphate, and the phosphosites were mapped to serine residues (Castano et al., 1996; Mason et al., 1996). Indeed, $\alpha 7$ has an acidic $C$-terminal tail that contains two conserved serines (ES ${ }_{243}$ LKEEDES $_{250}$ DDDNM), both of which could be phosphorylated by CK2 (recognizing S/TXXE/D/pS motifs) in vitro as shown by mutagenesis studies (Castano et al., 1996; Bose et al., 2004). Nonetheless, none of these studies proved that CK2 is the physiological kinase for $20 \mathrm{~S}$ phosphorylation.

What is the functional relevance of such phosphorylations? Rivett's group demonstrated that $\alpha 7$ and $\alpha 3$ were phosphorylated in both $20 \mathrm{~S}$ and $26 \mathrm{~S}$ proteasomes (Mason et al., 1996), but they were much dephosphorylated by interferon gamma (IFN- $\gamma$ ) treatment with a concomitant decrease of $26 \mathrm{~S}$ proteasome content and increase in 11S/ PA28-containing proteasomes in cells (Bose et al., 2001). $\alpha 7$ mutants with either $\mathrm{S} 243$ or $\mathrm{S} 250$ or both sites changed to alanine seemed to be excluded from $26 \mathrm{~S}$ complexes. Therefore, $\alpha 7$ appears to be constitutively phosphorylated to stabilize the 26S proteasome. Its dephosphorylation following IFN-y signaling promotes the switch to 11S-activated proteasomes that are important for downstream immune responses (Rivett et al., 2001; Bose et al., 2004). However, whether IFN-y specifically induces $\alpha 7$ dephosphorylation at S243/S250 and the underlying mechanism have not been elucidated.

It is noteworthy that $\alpha 7-S 250$ is by far the most frequently detected proteasome phosphorylation site (found in $>900$ spectra curated at PhosphoSitePlus). Treating cells with phosphatase inhibitors Calyculin A and okadaic acid did not further increase S250 phosphorylation (Mason et al., 1998), indicating that it is probably constitutive as revealed by a recent MS study (Gersch et al., 2015). Interestingly, throughout evolution, the very $\mathrm{C}$-terminal end of $\alpha 7$ is rich in acidic residues. In $S$. cerevisiae it also contains three phosphorylation sites that are important for binding to the 


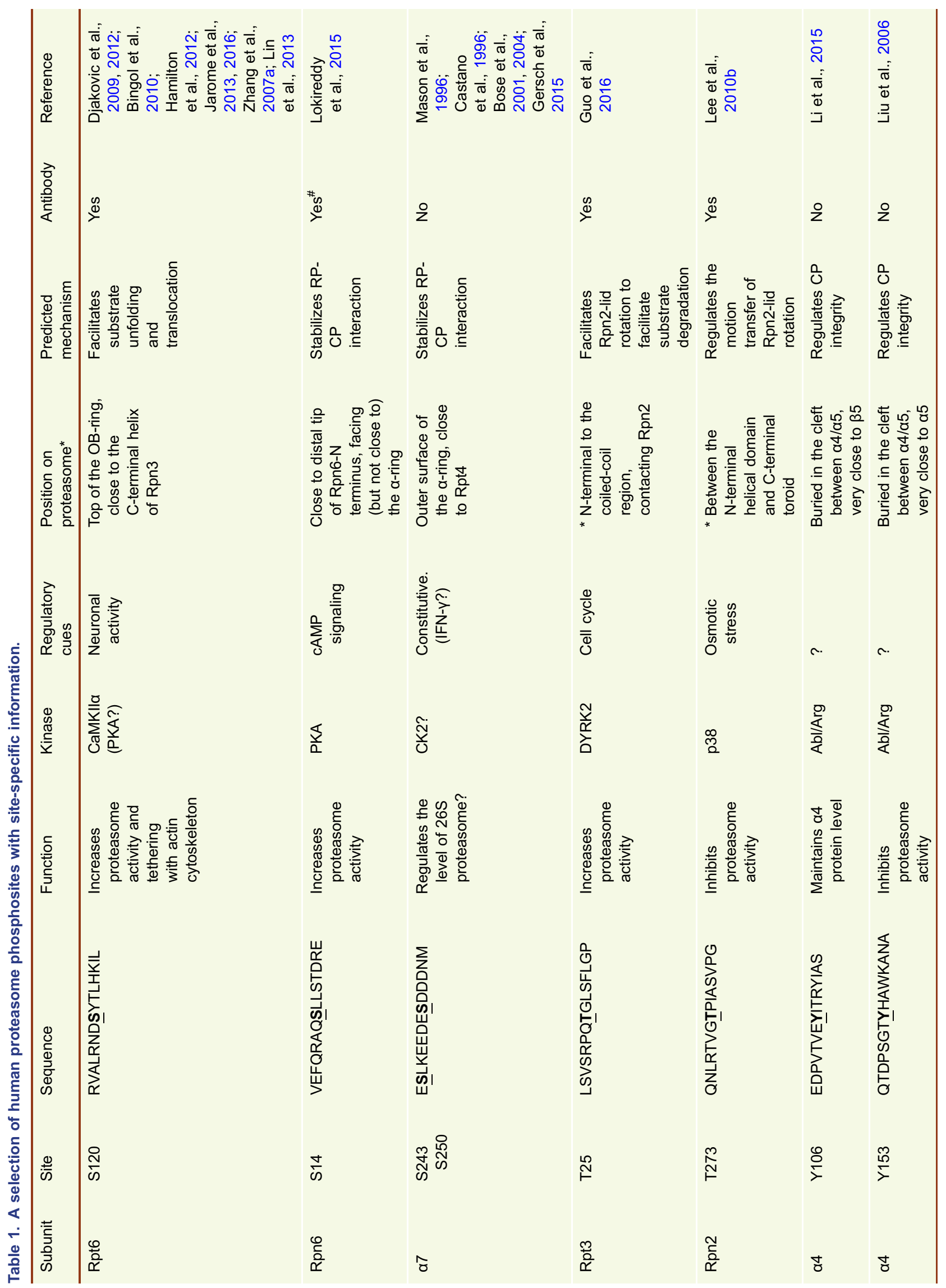




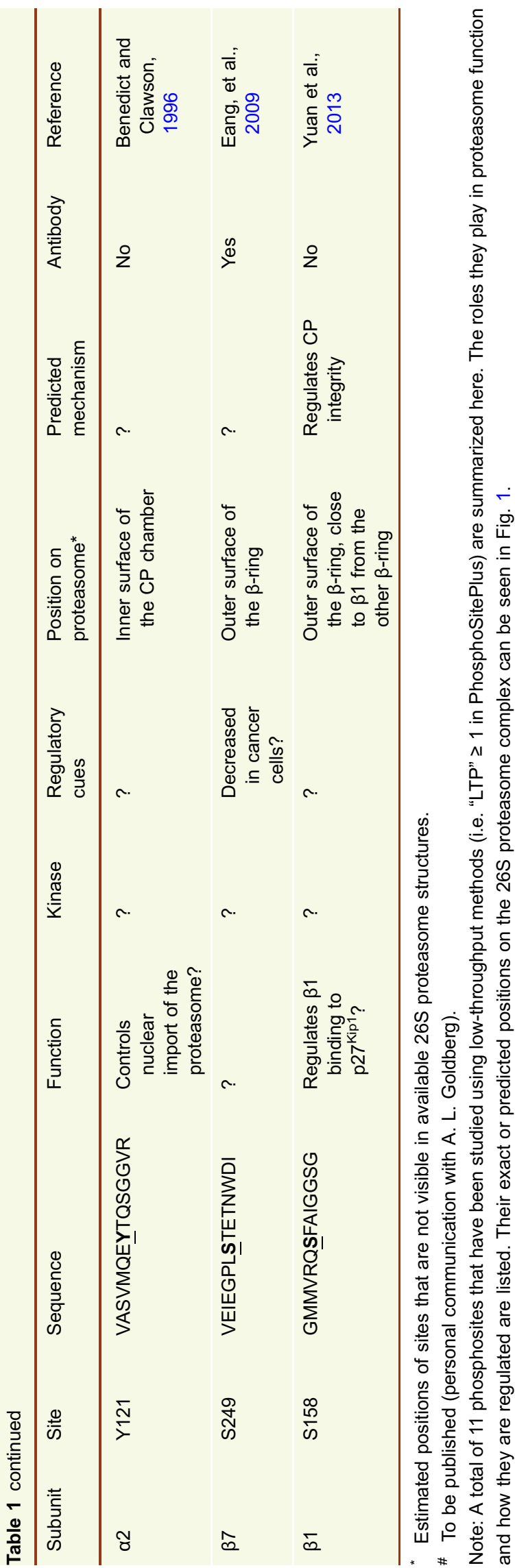

proteasome quality control factor, Ecm29 (Wani et al., 2016). Whether this holds true for human $\alpha 7$ is unknown. In addition, S250 phosphorylation changes during stem cell differentiation, cell cycle and with exposure to anti-cancer drugs (Brill et al., 2009; Dulla et al., 2010; Schmidt et al., 2011; Imami et al., 2012). It is unclear how this happens since CK2 is generally considered to be always active. In fact, there is even evidence against CK2 since its inhibition actually increased a7-S250 phosphorylation (Franchin et al., 2015). Therefore, the regulation and biological function of this heavily phosphorylated site remain to be rigorously examined (Table 1).

\section{CaMKIla}

Neuronal synapse formation, maintenance, and plasticity involve drastic changes in the composition of synaptic proteins, and the UPS plays an essential role in controlling local protein turnover during these processes (Ehlers, 2003; Bingol and Sheng, 2011). In response to neuronal activity, the 26S proteasome complex not only becomes physically sequestered in dendritic spines (Bingol and Schuman, 2006) but also exhibits elevated activity (Djakovic et al., 2009). Intriguingly, both phenomena depend on the kinase CaMKlla, one of the most abundant proteins in the brain and a master regulator of synapses.

Patrick and colleagues first reported that treating hippocampal neurons with bicuculline (BIC, to upregulate action potentials) increased proteasome activity while tetrodotoxin (TTX, an action potential blocker) produced the opposite effect. BIC-induced proteasome activation in neurons was abrogated by CaMKII inhibitors, whereas the constitutively active T286D mutant (mimicking the autophosphorylated form) of CaMKIla was sufficient to increase proteasome activity in both neurons and 293T cells. Purified CaMKIla phosphorylated the aforementioned Rpt6-S120 site in vitro and was therefore established as a new proteasome-regulating kinase (Djakovic et al., 2009).

Soon after, CaMKIla was demonstrated to be a PIP in vivo as it co-purifies with $26 \mathrm{~S}$ proteasomes from synaptosome-enriched fractions of rat forebrain. Autophosphorylated CaMKIla shows better proteasome binding and is both necessary and sufficient for proteasome redistribution to dendritic spines upon NMDA stimulation, resulting in efficient synaptic protein degradation (Bingol et al., 2010). Although this scaffolding function was shown to be independent of CaMKIla kinase activity toward Rpt6-S120, proteasomes containing the Rpt6-S120D mutant seemed to be more resistant to detergent extraction in hippocampal neurons (Djakovic et al., 2012). Therefore, CaMKIla-mediated Rpt6S120 phosphorylation may also contribute to proteasome tethering at the spines. Functionally, blockade of this phosphorylation by the S120A mutation or CaMKIla inhibition reduces synaptic activity and prevents activity-induced spine growth (Djakovic et al., 2012; Hamilton et al., 2012). Furthermore, in rats, fear conditioning as well as fear memory 
retrieval increases proteasome activity and Rpt6-S120 phosphorylation in amygdala in a CaMKIla-dependent manner. Both pharmacological inhibition of CaMKIla and S120A knock-in lead to defects of learning and memory in rodents (Jarome et al., 2013; Jarome et al., 2016 and personal communications with G. Patrick), strongly supporting the physiological significance of such phospho-regulation of the proteasome (Table 1).

\section{DYRK2}

The cell cycle is driven by ordered and finely regulated proteasomal degradation of many proteins such as cyclins, cyclin-dependent kinase (CDK) inhibitors, and licensing and check point factors. As a central regulator of cell cycle, the 26S proteasome itself contains multiple residues that are phosphorylated at different cell cycle stages (Dephoure et al., 2008; Nagano et al., 2009; Olsen et al., 2010; Kettenbach et al., 2011). The first kinase that has a clear role in cell cycle-dependent proteasome phosphorylation turns out to be DYRK2 (Guo et al., 2016), a member of the dualspecificity tyrosine phosphorylation regulated kinase family (Becker, 2012).

Unlike PKA, CK2, and CaMKIla that were all identified with targeted approaches, DYRK2 was discovered in an unbiased screen for kinases that phosphorylate a particular site of the proteasome, Rpt3-Thr25 (Table 1). This phosphosite was first detected in mitotic HeLa cells by MS (Dephoure et al., 2008) then confirmed in multiple cell types with a phospho-specific antibody (Guo et al., 2016). As seen with Rpt6-S120 and Rpn6-S14, phosphorylation of Rpt3-T25 also upregulates proteasome activity towards peptide and folded protein substrates in vitro and in cells. Interestingly, Rpt3-T25 phosphorylation occurs only in actively proliferating cells, with its level being low in $\mathrm{G}_{1}$ phase but markedly elevated during $S, G_{2}$, and $M$ phases of the cell cycle. CRISPR/Cas9-mediated knock-in of Rpt3-T25A mutation, which reduces endogenous proteasome activity, causes marked accumulation of cell cycle inhibitors such as p21 Cip1 and $\mathrm{p} 27^{\mathrm{Kip} 1}$ during S-to- $\mathrm{G}_{2} / \mathrm{M}$ transition and impedes cell proliferation. This is the first example that a phosphorylation event coordinates proteasome activity with cell cycle progression (Guo and Dixon, 2016; Guo et al., 2016).

Given the biochemical and biological importance of Rpt3T25 phosphorylation, a human kinase cDNA library from the laboratory of the late Dr. Susan L. Lindquist (Taipale et al., 2012) was used to screen for the responsible kinase(s). An unexpected kinase, DYRK2, was found to strongly phosphorylate T25 in vitro and in cells, while its disruption by CRISPR/Cas9 essentially abolished the phosphorylation. The adjacent sequence of T25 (RPXT) is conserved in vertebrates and is a known substrate motif of DYRK family kinases (Howard et al., 2014). DYRK2-null cells exhibit lowered proteasome activity and slowed proliferation, phenocopying Rpt3-T25A knock-in. In keeping with the dynamics of Rpt3-T25 phosphorylation during cell cycle, DYRK2 itself is transcriptionally induced upon $S$ phase entry. This leads to upregulation of T25 phosphorylation and efficient proteasomal degradation of key proteins like $\mathrm{p} 21^{\mathrm{Cip} 1}$ and p2 $7^{\mathrm{Kip} 1}$, which in turn facilitates cell cycle progression (Guo et al., 2016; Huibregtse and Matouschek, 2016).

As discussed above, proteasome activity can be manipulated in vivo by changing its phosphorylation status, offering new possibilities for proteasome-oriented therapies. Several types of cancer are exquisitely dependent on proteasome activity for survival, including basal-like triple negative (ER ${ }^{-}$/ $\mathrm{PR}^{-} / \mathrm{HER}^{-}$) breast cancer (Petrocca et al., 2013). Inactivation of DYRK2 sensitized these cancer cells to the proteasome inhibitor Bortezomib in vitro, and blockade of Rpt3-T25 phosphorylation significantly attenuated their tumorigenecity in vivo (Guo et al., 2016). In addition, DYRK2 gene is amplified in a considerable fraction of cancers (Santarius et al., 2010) and its mRNA level negatively correlates with clinical outcome of breast cancer patients (Guo et al., 2016). Therefore, simultaneous targeting of DYRK2 and the proteasome may be a promising combinatorial approach for treating certain cancers, as supported by preliminary data from ongoing research.

\section{PKG}

The post-mitotic cardiomyocytes, like neurons, are particularly vulnerable to damaged, misfolded, and aggregated proteins. With a major role in the clearance of cytotoxic proteins, the UPS is essential for the health of cardiomyocytes but its function is often impaired in heart disease. Enhancing the degradative capacity of cardiac proteasomes may therefore provide a way for heart disease control and treatment. An attractive strategy appears to be through activation of protein kinase $G$ (PKG), a key regulator of cellular functions in the cardiovascular system (Rainer and Kass, 2016).

PKG is activated by the small-molecule second messenger cyclic guanosine 3'-5' monophosphate (cGMP). Sildenafil, a phosphodiesterase 5 inhibitor which raises cGMP levels, enhanced proteasome activity in neonatal rat ventricular myocytes, while PKG inactivation caused the opposite effects (Ranek et al., 2013). Importantly, in vivo administration of sildenafil effectively reduced protein aggregation and hypertrophy in cardiac tissues of transgenic mice expressing $\mathrm{CryAB}^{\mathrm{R} 120 \mathrm{G}}$, a mutant protein whose misfolding causes desmin-related cardiomyopathy. Indirect evidence suggested that PKG may be involved Rpt6 and $\beta 5$ phosphorylation in cells (Ranek et al., 2013). Although the phosphorylation sites remain to be elucidated, this study provides mechanistic insights into the established anti-hypertrophy function of sildenafil and therefore may have profound clinical importance (Gillette and Hill, 2013).

\section{Other Ser/Thr kinases}

Multiple lines of evidence suggest that polo-like kinase 1 (Plk1) is a proteasome kinase. Plks are activated during 
$\mathrm{G}_{2} / \mathrm{M}$ transition of the cell cycle and regulate key events of mitosis (van de Weerdt and Medema, 2006). Plk1, probably via its polo-box domain, can directly interact with most $20 S$ subunits and some 19S subunits (Lowery et al., 2007; Dephoure et al., 2008). The $20 \mathrm{~S}$ proteasome has been shown to be phosphorylated (especially at the $\alpha 3$ and $\alpha 7$ subunits) and activated in vitro by Plk1 pre-treated with OA or mitotic lysates (Feng et al., 2001). On the other hand, Plk1 inhibitors reduce or block the phosphorylation of several proteasome subunits (Grosstessner-Hain et al., 2011; Kettenbach et al., 2011; Santamaria et al., 2011). The exact phosphorylation sites and the function of Plk1-mediated proteasome regulation in mitosis remain to be determined.

As opposed to the above examples, several other Ser/Thr kinases appear to negatively regulate proteasome activity. For example, the p38 MAPK phosphorylates Rpn2-Thr273 upon sorbitol-induced osmotic stress, leading to decreased peptidase activity of the proteasome without changing its assembly (Lee et al., 2010b, Table 1). This phosphorylation also increases with high $\mathrm{NaCl}$ treatment (Wang et al., 2014). Another MAPK, ERK2, could phosphorylate Rpn2-T273 in vitro (Tsai et al., 2015). In brain slices from mouse hippocampal CA1 region, long-term potentiation (LTP) stimulation decreased Rpn2-T273 phosphorylation by an unknown mechanism ( $\mathrm{Li}$ et al., 2016), presumably leading to an increase in proteasome activity as seen with CaMKIla activation.

Other stress inducers, such as $\mathrm{H}_{2} \mathrm{O}_{2}$ or the DNA topoisomerase inhibitor etoposide that signal through the ASK1JNK1 pathway, can also inhibit the proteasome. This inhibition requires ASK1, which can bind the ATPase subunits and phosphorylate Rpt5, leading to decreased proteasome ATPase activity hence substrate degradation in vitro and in vivo (Um et al., 2010). Another possible inhibitory kinase is AMPK. Several AMPK activators, including AICAR, Metformin and A-769662, could downregulate 26S proteasome activity, while genetic deletion of AMPKa2 did the opposite (Moreno et al., 2008; Viana et al., 2008; Wang et al., 2010). However, the mechanisms and physiological meanings of these regulations have yet to be uncovered.

\section{Abl/Arg and proteasome tyrosine phosphorylation}

$\mathrm{C}-\mathrm{Abl}$ and the related protein Arg (Abl-related gene product) are multi-functional tyrosine kinases and are so far the only tyrosine kinases shown to directly phosphorylate and regulate the proteasome (Liu et al., 2006; Li et al., 2015). Abl was found in a yeast two-hybrid screen to interact with the $20 \mathrm{~S}$ subunit a4/PSMA7. Both Abl and Arg phosphorylate $\alpha 4$ at two conserved tyrosine residues, Y106 and Y153 (Table 1). However, these phosphorylations seem to have opposite effects on proteasome function. Y153 phosphorylation reduced proteasome activity in vitro and in cells, whereas Y106 phosphorylation protected $\alpha 4$ from degradation by the proteasome. As a result, the $26 \mathrm{~S}$ holoenzyme was low in abundance but high in activity in Abl/Arg double knockout cells, leading to little net change in the overall degradation capacity as compared to WT cells. Albeit the proteotoxic effect of oxidative stress appeared more evident in the absence of Abl and Arg (Li et al., 2015), the physiological significance of a4 tyrosine phosphorylation remains nebulous.

Except for these studies, almost nothing is known about the function and regulation of proteasome tyrosine phosphorylation. Many tyrosine residues of human 26S proteasome reported to be phosphorylated are conserved even in yeast, which is surprising in light of the limited overlap of proteasome phosphosites between the two species and the evolutionary reduction of tyrosine phosphorylation in higher organisms (Tan et al., 2009). Since yeast genome does not encode conventional tyrosine kinases (Manning et al., 2002) and yeast proteasome is rarely tyrosine-phosphorylated (PhosphoGrid), those conserved tyrosine residues presumably play structural rather than regulatory roles. As mentioned earlier, the $\mathrm{HbYX}$ motif at the C-terminal tails of Rpt2, 3 , and 5 are critical for bolting the $19 S$ and $20 S$ particles together. However, the penultimate tyrosines within this motif of human Rpt2 and Rpt3 seem to be more frequently phosphorylated than any other pY site of the 19S RP. Such phosphorylations would undoubtedly preclude RP-CP interaction, therefore must happen on free 19S RP (if they truly happen in cells), perhaps as a prerequisite or checkpoint for 19S RP assembly and/or 26S proteasome formation.

MS results indicate that $\mathrm{pY}$ sites are spread all over the $26 S$ complex and they constitute an astounding 1/3 (150/ $455)$ of all known proteasome phosphosites. Moreover, 11 out of the top 12 most frequently detected proteasome phosphorylations (i.e. sites with HTP > 100 from PhosphoSitePlus) occur on tyrosine residues (Table S1). Such over-representation of $\mathrm{pY}$ in the proteasome complex is, at first sight, quite striking as $p Y$ is generally perceived as a very minor portion of the whole phosphoproteome (Hunter and Sefton, 1980; Olsen et al., 2006; Sharma et al., 2014; Bian et al., 2016). However, it should be emphasized that most proteasome tyrosine phosphorylations were observed by MS following treating cells with pervanadate (a potent non-specific inhibitor of protein tyrosine phosphatases, or PTPs) and enrichment of peptides with anti-pY antibodies. In fact, few tyrosines have been found phosphorylated on endogenous proteasome proteins from mouse tissues (PhosphoMouse), and affinity-purified proteasomes from untreated human cells contain very little $p Y$ signal as shown by Western blot (our unpublished results). Together, these observations strongly suggest that, although the proteasome may be constantly phosphorylated by tyrosine kinases, the modification must occur at a low stoichiometry and are very sensitive to dephosphorylation by PTPs. Identification of the relevant tyrosine kinases and PTPs will shed light on why proteasome tyrosine phosphorylation happens but is kept under such tight control.

On the other hand, numerous studies have reported significant increases of proteasome tyrosine phosphorylation, 
which invariably took place in cancer cells with aberrant tyrosine kinase signaling (Rush et al., 2005; Gu et al., 2006; Rikova et al., 2007; Guo et al., 2008; Luo et al., 2008; Iliuk et al., 2010; Bai et al., 2012; Drake et al., 2012; Johnson et al., 2012). Most of the deregulated pY sites locate on $20 \mathrm{~S}$ subunits, especially $\alpha 2$, whose $\mathrm{Y} 24, \mathrm{Y} 57, \mathrm{Y} 76$, and $\mathrm{Y} 101$ residues appear to be "hot spots" targeted by oncogenic tyrosine kinases. Considering the prevalent upregulation of proteasome activity in various types of cancer (Hoeller and Dikic, 2009), in-depth understanding of proteasome tyrosine phosphorylation may provide new insights into cancer pathogenesis, diagnosis, and treatment.

\section{UBLCP1 and proteasome phosphatases}

The generally low stoichiometry of proteasome phosphorylations (especially $\mathrm{pY}$ ) and the necessity of phosphatase inhibitors for their detection strongly indicate a significant role of dephosphorylation in controlling proteasome functions. However, compared to the kinases, proteasome phosphatases have been even less investigated. Evidence exists that treating the proteasome with common phosphatases (such as PP1 and PP2A family members) or nonspecific phosphatases (such as $\lambda$-phosphatase, alkaline/ acidic phosphatases) can reduce the peptidase activities in vitro (Mason et al., 1996; Zong et al., 2006; Zhang et al., 2007a; Kikuchi et al., 2010; Guo et al., 2011). In addition, PP2A subunits and Calcineurin subunits have been shown to be in complex with the 20S proteasome (Zong et al., 2006; Li et al., 2011; Zhang and Wei, 2011), but their roles in proteasome regulation are far from clear. At present, the only physiological proteasome phosphatase that has been functionally characterized is ubiquitin-like domain containing CTD phosphatase 1 (UBLCP1).

UBLCP1 belongs to the haloacid dehalogenase (HAD) family of phospho-Ser/Thr phosphatases that consists of at least seven members in mammals. Unlike founding members of this family, SCP1 and FCP1, which are known to dephosphorylate the C-terminal domain (CTD) of RNA polymerase II (Pol II), UBLCP1 does not interact with or regulate Pol II. Instead, it is targeted to the 265 proteasome via its UBL domain (Guo et al., 2011). In fact, UBLCP1 is the only phosphatase in the human phosphatome that contains a UBL domain, making it the first and only known proteasome-resident phosphatase. Knockdown of UBLCP1 enhances proteasome activity in cells, while in vitro UBLCP1 directly dephosphorylates multiple subunits of purified 26S proteasome and reduces its activity. Therefore, UBLCP1 negatively regulates proteasome function, in a manner that relies on both its phosphatase activity and direct interaction with the proteasome. One mechanism for this regulation is that UBLCP1 prevents 19S-20S association (or promotes 26S dissociation), thereby attenuating the overall proteasome activity (Guo et al., 2011). However, the exact phosphosites modulated by UBLCP1 were not identified.
Another important property of UBLCP1 is that it is a nuclear protein without a canonical nuclear localization signal (NLS). Its exclusive nuclear localization is strictly dependent on a single conserved lysine residue (K44) within the UBL domain, which is also critical for UBLCP1 binding to the proteasome. Thus, UBLCP1 selectively downregulates nuclear proteasome without affecting cytoplasmic proteasome (Guo et al., 2011). This work, together with previously mentioned synaptic retention of proteasomes by CaMKIla (Bingol et al., 2010; Djakovic et al., 2012), demonstrates compartmentalized proteasome regulation and highlights the cellular heterogeneity of proteasomes that is usually masked by using cell/tissue homogenates (Sha et al., 2011; Schmidt and Finley, 2014).

Owing to the unique structure of UBLCP1 catalytic domain (Guo et al., 2011), a small-molecule inhibitor was identified from a high-content screen that is both potent and specific against this phosphatase. Treating cells with this inhibitor caused an increase of nuclear proteasome activity, consistent with UBLCP1 being a negative regulator of nuclear proteasomes (He et al., 2015). This effect is analogous to that of inhibiting USP14, a proteasome-associated deubiquitinating enzyme (Lee et al., 2010a), both employing an "inhibition-of-an-inhibitor" strategy to achieve proteasome activation. Given the impaired proteasome function in neurodegenerative and heart diseases, these compounds may represent a different approach than PKA activators (See above) for therapeutics.

\section{HOW DOES PHOSPHORYLATION MODULATE PROTEASOME FUNCTION?}

In principle, a phosphorylation event can positively or negatively impact any aspect of proteasome function and any step during its biogenesis. This view has been more or less proven by available examples from largely isolated studies as described above. Collectively, phosphorylation can regulate (i) protein stability and abundance of certain subunits (Li et al., 2015), (ii) proteasome assembly, stability or composition (Satoh et al., 2000; Bose et al., 2004; Guo et al., 2011; Lokireddy et al., 2015), (iii) subcellular localization of the proteasome (Benedict and Clawson, 1996; Bingol et al., 2010; Djakovic et al., 2012), (iv) PIP binding (Wani et al., 2016), (v) substrate recognition (Satoh et al., 1995; Yuan et al., 2013), and (vi) enzymatic activities (Mason et al., 1996; Liu et al., 2006; Zong et al., 2006; Djakovic et al., 2009; Bingol et al., 2010; Guo et al., 2016).

Phosphorylations often take place at flexible loops and disordered regions of proteins (Holt et al., 2009), posing a potential challenge for structural analysis. Indeed, despite biochemical and functional evidence, no structural basis is available for any of the proteasome phosphosites, leaving a big gap in our understanding of how exactly their phosphorylations alter proteasome properties. Take DYRK2-mediated Rpt3-T25 phosphorylation as an example, it is located 
near the extreme $\mathrm{N}$-terminus of Rpt3, a highly dynamic region invisible in all crystal and cryo-EM structures of the proteasome. However, it is likely tucked under Rpn2 and regulates the rotation of Rpn2 and $19 S$ lid around the fulcrum formed by the Rpt3-Rpt6 coiled-coil (Matyskiela et al., 2013). Such rotation is believed to be coupled with substrate unfolding and translocation, consistent with biochemical studies showing that Rpt3-T25 phosphorylation enhances substrate-stimulated ATPase activity of the proteasome (Guo et al., 2016). Interestingly, although T25 is not conserved in yeast Rpt3, the latter has a nearby residue, Thr8, that has been found to be dynamically phosphorylated during cell cycle (L. Huang, personal communication). Despite that the exact site and (probably) the responsible kinase are different, it is tempting to postulate that phosphorylation at the very $\mathrm{N}$-terminus of human and yeast Rpt3 may have similar functions, therefore might be considered as "functionally conserved". Such scenario has been observed for other phosphorylation events (Holt et al., 2009) as well as other post-translational modifications (Xu et al., 2013). Figure 1 illustrates the observed or predicted positions of several functionally relevant phosphosites on the high-resolution cryo-EM structure of human 26S proteasome (Huang et al., 2016), and their speculated roles in proteasome regulation are summarized in Table 1. Clearly more biophysical and structural insights are needed to fully explain the molecular mechanisms for phosphoregulation of the proteasome.

\section{PROSPECTS}

How do we go further in understanding proteasome phosphorylation? The simple answer is that we need to go broader and go deeper. On one hand, previous research on proteasome phosphorylation has been isolated and mostly relied candidate approaches. More systematic screens are needed to identify kinases and phosphatases that regulate proteasome activity and phosphorylation profile. Libraries of cDNAs, shRNAs, sgRNAs, and small-molecule inhititors are readily available for this purpose and have been successfully used (Chou and Deshaies, 2011; Guo et al., 2016). Knowledge about proteasome kinases and phosphatases is instrumental because it not only allows for direct manipulation of proteasome phosphorylation for biochemical analysis in vitro and in vivo, but also helps to elucidate the biological meaning of proteasome phosphorylation by connecting it with signaling pathways and cellular activities.

On the other hand, description of proteasome phosphorylation in proteomic studies has been superficial and it is necessary to dig deeper into the function and regulation of individual events. Phospho-specific antibodies, site-directed mutagenesis and targeted MS have been and will still be the prevalent methods for characterizing the phosphosites. A high quality phospho-antibody would be particularly useful for determining the intracellular localization of phosphorylated proteasomes, a critical question with little investigation. It will also facilitate the search for relevant kinases and phosphatases. Overexpression of proteasome subunits bearing phosphosite mutations may or may not yield a change in proteasome activity in cells, since the endogenous wild-type proteins are usually highly abundant, and epitopetagged exogenous mutants may not be fully incorporated into the proteasome complex. In this sense, homozygous knock-in of point mutations using gene editing tools such as CRISPR/Cas9 can unequivocally reveal the functional requirement of proteasome phosphorylation, as has been demonstrated (Guo et al., 2016). New methods and instrumentation for quantitative MS are needed for more sensitive and accurate capture of transient, dynamic, and low-abundance phosphorylations.

On a separate note, in addition to serine, threonine and tyrosine, phosphorylation also occurs on other residues such as histidine. The recent development of monoclonal antibodies against phospho-histidine has redefined our view of such modifications in human cells (Fuhs et al., 2015). Intriguingly, a considerable fraction of the histidine-phosphorylated proteome is comprised of proteasome subunits (Fuhs et al., 2015). This finding recalls previously identified phosphohistidine residues in $20 \mathrm{~S}$ subunits (Yano et al., 1999), and yet the physiological function and regulation of proteasome histidine phosphorylation are not known.

\section{CONCLUDING REMARKS}

All of the above research has vividly demonstrated the heterogeneity and complexity of the proteasome, and has shattered the stereotypic view that the proteasome is a "boring" house-keeping machinery. Reversible phosphorylation fine-tunes proteasome activity and adds a new layer of regulation to proteostasis, the basis of all cellular life. The exquisite control of conserved phosphosites reflects highly specialized needs for coordinating proteasome function with specific physiological activities during evolution, which we still know very little about. Research in this field urgently calls for advanced experimental systems and tools such as single-molecule recording, in situ electron cryotomography, super-resolution microscopy, quantitative cross-linking MS, as well as other new biochemical/biophysical methods, pharmacological agents, antibodies, and animal models (Pack et al., 2014; Asano et al., 2015; Lu et al., 2015). Development of these tools will also benefit research on other aspects of proteasome regulation and on macromolecular complexes in general.

Proteasome phosphorylation is not only of biological significance but also clinically relevant. Proteasome inhibitors as anti-cancer drugs cannot distinguish between cancer cells and normal cells, which, however, often differ drastically in their phospho-signaling. Therefore, targeting both the proteasome itself and its modulators deregulated in cancer cells is expected to increase the efficacy of proteasome inhibitors, improve drug selectivity, and even partly overcome drug resistance. Conversely, proteasome activation can be beneficial in treating neurodegenerative and heart 
diseases, which can be achieved by kinase activators (as in the case of PKA and PKG) or phosphatase inhibitors (as in the case of UBLCP1). In-depth understanding of proteasome phosphorylation will greatly expand the repertoire of biochemicals that can be used for proteasome modulation, providing more choices for proteasome-based regimens in the clinic.

\section{ACKNOWLEDGEMENTS}

This work was supported by the startup funding from Zhejiang University, Fundamental Research Funds for the Central Universities (2016QN81011) and National Natural Science Foundation of China (31671391) to X.G. M.J.C is supported by the Genentech postdoctoral program.

\section{ABBREVIATIONS}

CDK, cyclin-dependent kinase; cGMP, cyclic guanosine 3'-5' monophosphate; $\mathrm{CP}$, core particle; CTD, C-terminal domain; HAD, haloacid dehalogenase; IFN- $\gamma$, interferon gamma; LTP, long-term potentiation; MS, mass spectrometry; NLS, nuclear localization signal; OA, okadaic acid; OB, oligonucleotide-binding; PIPs, proteasome-interacting proteins; PKA, protein kinase $A ; P K G$, protein kinase G; PIk1, polo-like kinase 1; pS, phospho-serine; pT, phosphothreonine; PTPs, protein tyrosine phosphatases; pY, phosphotyrosine; RP, regulatory particle; UBL, ubiquitin-like; TTX, tetrodotoxin; UBLCP1, ubiquitin-like domain containing CTD phosphatase 1.

\section{COMPLIANCE WITH ETHICS GUIDELINES}

Xing Guo, Xiuliang Huang, and Mark J. Chen declare that they have no conflict of interest. This article does not contain any studies with human or animal subjects performed by the any of the authors.

\section{OPEN ACCESS}

This article is distributed under the terms of the Creative Commons Attribution 4.0 International License (http://creativecommons.org/ licenses/by/4.0/), which permits unrestricted use, distribution, and reproduction in any medium, provided you give appropriate credit to the original author(s) and the source, provide a link to the Creative Commons license, and indicate if changes were made.

\section{REFERENCES}

Asai M, Tsukamoto O, Minamino T, Asanuma $\mathrm{H}$, Fujita M, Asano $\mathrm{Y}$, Takahama H, Sasaki H, Higo S, Asakura M et al (2009) PKA rapidly enhances proteasome assembly and activity in in vivo canine hearts. J Mol Cell Cardiol 46:452-462

Asano S, Fukuda Y, Beck F, Aufderheide A, Forster F, Danev R, Baumeister W (2015) Proteasomes. A molecular census of $26 S$ proteasomes in intact neurons. Science 347:439-442

Bai Y, Li J, Fang B, Edwards A, Zhang G, Bui M, Eschrich S, Altiok S, Koomen J, Haura EB (2012) Phosphoproteomics identifies driver tyrosine kinases in sarcoma cell lines and tumors. Cancer Res 72:2501-2511

Bardag-Gorce F, Venkatesh R, Li J, French BA, French SW (2004) Hyperphosphorylation of rat liver proteasome subunits: the effects of ethanol and okadaic acid are compared. Life Sci 75:585-597

Beausoleil SA, Villen J, Gerber SA, Rush J, Gygi SP (2006) A probability-based approach for high-throughput protein phosphorylation analysis and site localization. Nat Biotechnol 24: 1285-1292

Becker W (2012) Emerging role of DYRK family protein kinases as regulators of protein stability in cell cycle control. Cell Cycle 11:3389-3394

Benedict CM, Clawson GA (1996) Nuclear multicatalytic proteinase subunit RRC3 is important for growth regulation in hepatocytes. Biochemistry 35:11612-11621

Bian Y, Li L, Dong M, Liu X, Kaneko T, Cheng K, Liu H, Voss C, Cao $X$, Wang $Y$ et al (2016) Ultra-deep tyrosine phosphoproteomics enabled by a phosphotyrosine superbinder. Nat Chem Biol 12:959-966

Bingol B, Schuman EM (2006) Activity-dependent dynamics and sequestration of proteasomes in dendritic spines. Nature 441:1144-1148

Bingol B, Sheng M (2011) Deconstruction for reconstruction: the role of proteolysis in neural plasticity and disease. Neuron 69:22-32

Bingol B, Wang C-F, Arnott D, Cheng D, Peng J, Sheng M (2010) Autophosphorylated CaMKIla acts as a Scaffold to recruit proteasomes to dendritic spines. Cell 140:567-578

Bose S, Brooks P, Mason GG, Rivett AJ (2001) gamma-Interferon decreases the level of $26 \mathrm{~S}$ proteasomes and changes the pattern of phosphorylation. Biochem J 353:291-297

Bose S, Stratford FL, Broadfoot KI, Mason GG, Rivett AJ (2004) Phosphorylation of $20 \mathrm{~S}$ proteasome alpha subunit C8 (alpha7) stabilizes the $26 \mathrm{~S}$ proteasome and plays a role in the regulation of proteasome complexes by gamma-interferon. Biochem $\mathrm{J}$ 378:177-184

Brill LM, Xiong W, Lee KB, Ficarro SB, Crain A, Xu Y, Terskikh A, Snyder EY, Ding S (2009) Phosphoproteomic analysis of human embryonic stem cells. Cell Stem Cell 5:204-213

Castano JG, Mahillo E, Arizti P, Arribas J (1996) Phosphorylation of C8 and C9 subunits of the multicatalytic proteinase by casein kinase II and identification of the C8 phosphorylation sites by direct mutagenesis. Biochemistry 35:3782-3789

Chen S, Wu J, Lu Y, Ma YB, Lee BH, Yu Z, Ouyang Q, Finley DJ, Kirschner MW, Mao Y (2016) Structural basis for dynamic regulation of the human $26 \mathrm{~S}$ proteasome. Proc Natl Acad Sci USA 113:12991-12996

Chou TF, Deshaies RJ (2011) Quantitative cell-based protein degradation assays to identify and classify drugs that target the ubiquitin-proteasome system. J Biol Chem 286:16546-16554

Choudhary C, Olsen JV, Brandts C, Cox J, Reddy PN, Bohmer FD, Gerke V, Schmidt-Arras DE, Berdel WE, Muller-Tidow C et al (2009) Mislocalized activation of oncogenic RTKs switches downstream signaling outcomes. Mol Cell 36:326-339

Cui Z, Scruggs SB, Gilda JE, Ping P, Gomes AV (2014) Regulation of cardiac proteasomes by ubiquitination, SUMOylation, and beyond. J Mol Cell Cardiol 71:32-42 
Dephoure N, Zhou C, Villen J, Beausoleil SA, Bakalarski CE, Elledge SJ, Gygi SP (2008) A quantitative atlas of mitotic phosphorylation. Proc Natl Acad Sci USA 105:10762-10767

Deveraux Q, Jensen C, Rechsteiner M (1995) Molecular cloning and expression of a $26 \mathrm{~S}$ protease subunit enriched in dileucine repeats. J Biol Chem 270:23726-23729

Djakovic SN, Schwarz LA, Barylko B, DeMartino GN, Patrick GN (2009) Regulation of the proteasome by neuronal activity and calcium/calmodulin-dependent protein kinase II. J Biol Chem 284:26655-26665

Djakovic SN, Marquez-Lona EM, Jakawich SK, Wright R, Chu C, Sutton MA, Patrick GN (2012) Phosphorylation of Rpt6 regulates synaptic strength in hippocampal neurons. J Neurosci 32:51265131

Djuranovic S, Hartmann MD, Habeck M, Ursinus A, Zwickl P, Martin J, Lupas AN, Zeth K (2009) Structure and activity of the $\mathrm{N}$-terminal substrate recognition domains in proteasomal ATPases. Mol Cell 34:580-590

Drake JM, Graham NA, Stoyanova T, Sedghi A, Goldstein AS, Cai $\mathrm{H}$, Smith DA, Zhang H, Komisopoulou E, Huang J et al (2012) Oncogene-specific activation of tyrosine kinase networks during prostate cancer progression. Proc Natl Acad Sci USA 109:16431648

Dulla K, Daub H, Hornberger R, Nigg EA, Korner R (2010) Quantitative site-specific phosphorylation dynamics of human protein kinases during mitotic progression. Mol Cell Proteomics 9:1167-1181

Eang R, Girbal-Neuhauser E, Xu B, Gairin JE (2009) Characterization and differential expression of a newly identified phosphorylated isoform of the human $20 \mathrm{~S}$ proteasome beta7 subunit in tumor vs. normal cell lines. Fundam Clin Pharmacol 23:215-224

Ehlers MD (2003) Activity level controls postsynaptic composition and signaling via the ubiquitin-proteasome system. Nat Neurosci 6:231-242

Ehlinger A, Walters KJ (2013) Structural insights into proteasome activation by the $19 S$ regulatory particle. Biochemistry 52:3618-3628

Feng Y, Longo DL, Ferris DK (2001) Polo-like kinase interacts with proteasomes and regulates their activity. Cell Growth Differ 12:29-37

Finley D (2009) Recognition and processing of ubiquitin-protein conjugates by the proteasome. Annu Rev Biochem 78:477-513

Finley D, Chen X, Walters KJ (2016) Gates, channels, and switches: elements of the proteasome machine. Trends Biochem Sci 41:77-93

Franchin C, Cesaro L, Salvi M, Millioni R, lori E, Cifani P, James P, Arrigoni G, Pinna L (2015) Quantitative analysis of a phosphoproteome readily altered by the protein kinase CK2 inhibitor quinalizarin in HEK-293T cells. Biochim Biophys Acta 1854:609623

Fuhs SR, Meisenhelder J, Aslanian A, Ma L, Zagorska A, Stankova M, Binnie A, Al-Obeidi F, Mauger J, Lemke $G$ et al (2015) Monoclonal 1- and 3-phosphohistidine antibodies: new tools to study histidine phosphorylation. Cell 162:198-210

Funakoshi M, Tomko RJ Jr, Kobayashi H, Hochstrasser M (2009) Multiple assembly chaperones govern biogenesis of the proteasome regulatory particle base. Cell 137:887-899
Gersch M, Hackl MW, Dubiella C, Dobrinevski A, Groll M, Sieber SA (2015) A mass spectrometry platform for a streamlined investigation of proteasome integrity, posttranslational modifications, and inhibitor binding. Chem Biol 22:404-411

Gillette TG, Hill JA (2013) PKG primes the proteasome. Circulation 128:325-327

Gnad F, Young A, Zhou W, Lyle K, Ong CC, Stokes MP, Silva JC, Belvin M, Friedman LS, Koeppen $\mathrm{H}$ et al (2013) Systems-wide analysis of K-Ras, Cdc42, and PAK4 signaling by quantitative phosphoproteomics. Mol Cell Proteomics 12:2070-2080

Goswami T, Li X, Smith AM, Luderowski EM, Vincent JJ, Rush J, Ballif BA (2012) Comparative phosphoproteomic analysis of neonatal and adult murine brain. Proteomics 12:2185-2189

Groll M, Ditzel L, Lowe J, Stock D, Bochtler M, Bartunik HD, Huber R (1997) Structure of $20 \mathrm{~S}$ proteasome from yeast at $2.4 \mathrm{~A}$ resolution. Nature 386:463-471

Grosstessner-Hain K, Hegemann B, Novatchkova M, Rameseder J, Joughin BA, Hudecz O, Roitinger E, Pichler P, Kraut N, Yaffe MB et al (2011) Quantitative phospho-proteomics to investigate the polo-like kinase 1-dependent phospho-proteome. Mol Cell Proteomics 10(M111):008540

Gu TL, Goss VL, Reeves C, Popova L, Nardone J, Macneill J, Walters DK, Wang Y, Rush J, Comb MJ et al (2006) Phosphotyrosine profiling identifies the KG-1 cell line as a model for the study of FGFR1 fusions in acute myeloid leukemia. Blood 108:4202-4204

Guo X, Dixon JE (2016) The 26S proteasome: a cell cycle regulator regulated by cell cycle. Cell Cycle 15:875-876

Guo A, Villen J, Kornhauser J, Lee KA, Stokes MP, Rikova K, Possemato A, Nardone J, Innocenti G, Wetzel R et al (2008) Signaling networks assembled by oncogenic EGFR and c-Met. Proc Natl Acad Sci USA 105:692-697

Guo X, Engel JL, Xiao J, Tagliabracci VS, Wang X, Huang L, Dixon JE (2011) UBLCP1 is a $26 \mathrm{~S}$ proteasome phosphatase that regulates nuclear proteasome activity. Proc Natl Acad Sci USA 108:18649-18654

Guo X, Wang X, Wang Z, Banerjee S, Yang J, Huang L, Dixon JE (2016) Site-specific proteasome phosphorylation controls cell proliferation and tumorigenesis. Nat Cell Biol 18:202-212

Haass C, Kloetzel PM (1989) The Drosophila proteasome undergoes changes in its subunit pattern during development. Exp Cell Res 180:243-252

Hamilton AM, Oh WC, Vega-Ramirez H, Stein IS, Hell JW, Patrick GN, Zito K (2012) Activity-dependent growth of new dendritic spines is regulated by the proteasome. Neuron 74:1023-1030

He Y, Guo X, Yu ZH, Wu L, Gunawan AM, Zhang Y, Dixon JE, Zhang ZY (2015) A potent and selective inhibitor for the UBLCP1 proteasome phosphatase. Bioorg Med Chem 23:2798-2809

Hoeller D, Dikic I (2009) Targeting the ubiquitin system in cancer therapy. Nature 458:438-444

Holt LJ, Tuch BB, Villen J, Johnson AD, Gygi SP, Morgan DO (2009) Global analysis of Cdk1 substrate phosphorylation sites provides insights into evolution. Science 325:1682-1686

Hough R, Pratt G, Rechsteiner M (1987) Purification of two high molecular weight proteases from rabbit reticulocyte lysate. J Biol Chem 262:8303-8313 
Howard CJ, Hanson-Smith V, Kennedy KJ, Miller CJ, Lou HJ, Johnson $A D$, Turk BE, Holt LJ (2014) Ancestral resurrection reveals evolutionary mechanisms of kinase plasticity. Elife 3:e04126

Huang X, Luan B, Wu J, Shi Y (2016) An atomic structure of the human 26S proteasome. Nat Struct Mol Biol 23:778-785

Huibregtse JM, Matouschek A (2016) Ramping up degradation for proliferation. Nat Cell Biol 18:141-142

Hunter T, Sefton BM (1980) Transforming gene product of Rous sarcoma virus phosphorylates tyrosine. Proc Natl Acad Sci USA 77:1311-1315

Husnjak K, Elsasser S, Zhang N, Chen X, Randles L, Shi Y, Hofmann K, Walters KJ, Finley D, Dikic I (2008) Proteasome subunit Rpn13 is a novel ubiquitin receptor. Nature 453:481-488

Iliuk AB, Martin VA, Alicie BM, Geahlen RL, Tao WA (2010) In-depth analyses of kinase-dependent tyrosine phosphoproteomes based on metal ion-functionalized soluble nanopolymers. Mol Cell Proteomics 9:2162-2172

Imami K, Sugiyama N, Imamura H, Wakabayashi M, Tomita M, Taniguchi M, Ueno T, Toi M, Ishihama Y (2012) Temporal profiling of lapatinib-suppressed phosphorylation signals in EGFR/HER2 pathways. Mol Cell Proteomics 11:1741-1757

Jarome TJ, Kwapis JL, Ruenzel WL, Helmstetter FJ (2013) CaMKII, but not protein kinase $A$, regulates Rpt6 phosphorylation and proteasome activity during the formation of long-term memories. Front Behav Neurosci 7:115

Jarome TJ, Ferrara NC, Kwapis JL, Helmstetter FJ (2016) CaMKII regulates proteasome phosphorylation and activity and promotes memory destabilization following retrieval. Neurobiol Learn Mem 128:103-109

Johnson H, Del Rosario AM, Bryson BD, Schroeder MA, Sarkaria JN, White FM (2012) Molecular characterization of EGFR and EGFRvIII signaling networks in human glioblastoma tumor xenografts. Mol Cell Proteomics 11:1724-1740

Kaneko T, Hamazaki J, lemura S, Sasaki K, Furuyama K, Natsume T, Tanaka K, Murata S (2009) Assembly pathway of the Mammalian proteasome base subcomplex is mediated by multiple specific chaperones. Cell 137:914-925

Kettenbach AN, Schweppe DK, Faherty BK, Pechenick D, Pletnev AA, Gerber SA (2011) Quantitative phosphoproteomics identifies substrates and functional modules of Aurora and Polo-like kinase activities in mitotic cells. Sci Signal 4:rs5

Kikuchi J, Iwafune Y, Akiyama T, Okayama A, Nakamura H, Arakawa N, Kimura Y, Hirano H (2010) Co- and post-translational modifications of the 26S proteasome in yeast. Proteomics 10:2769-2779

Kim BG, Lee JH, Ahn JM, Park SK, Cho JH, Hwang D, Yoo JS, Yates JR III, Ryoo HM, Cho JY (2009) 'Two-stage doubletechnique hybrid (TSDTH)' identification strategy for the analysis of BMP2-induced transdifferentiation of premyoblast $\mathrm{C} 2 \mathrm{C} 12$ cells to osteoblast. J Proteome Res 8:4441-4454

Kloetzel PM (2001) Antigen processing by the proteasome. Nat Rev Mol Cell Biol 2:179-187

Lee BH, Lee MJ, Park S, Oh DC, Elsasser S, Chen PC, Gartner C, Dimova N, Hanna J, Gygi SP et al (2010a) Enhancement of proteasome activity by a small-molecule inhibitor of USP14. Nature 467:179-184
Lee SH, Park Y, Yoon SK, Yoon JB (2010b) Osmotic stress inhibits proteasome by p38 MAPK-dependent phosphorylation. J Biol Chem 285:41280-41289

Li N, Zhang Z, Zhang W, Wei Q (2011) Calcineurin B subunit interacts with proteasome subunit alpha type 7 and represses hypoxia-inducible factor-1alpha activity via the proteasome pathway. Biochem Biophys Res Commun 405:468-472

Li D, Dong Q, Tao Q, Gu J, Cui Y, Jiang X, Yuan J, Li W, Xu R, Jin Y et al (2015) c-Abl regulates proteasome abundance by controlling the ubiquitin-proteasomal degradation of PSMA7 subunit. Cell Rep 10:484-496

Li J, Wilkinson B, Clementel VA, Hou J, O'Dell TJ, Coba MP (2016) Long-term potentiation modulates synaptic phosphorylation networks and reshapes the structure of the postsynaptic interactome. Sci Signal 9:rs8

Lin JT, Chang WC, Chen HM, Lai HL, Chen CY, Tao MH, Chern Y (2013) Regulation of feedback between protein kinase $A$ and the proteasome system worsens Huntington's disease. Mol Cell Biol 33:1073-1084

Liu X, Huang W, Li C, Li P, Yuan J, Li X, Qiu XB, Ma Q, Cao C (2006) Interaction between $\mathrm{C}-\mathrm{Abl}$ and Arg tyrosine kinases and proteasome subunit PSMA7 regulates proteasome degradation. Mol Cell 22:317-327

Livneh I, Cohen-Kaplan V, Cohen-Rosenzweig C, Avni N, Ciechanover A (2016) The life cycle of the $26 \mathrm{~S}$ proteasome: from birth, through regulation and function, and onto its death. Cell Res 26:869-885

Lokireddy S, Kukushkin NV, Goldberg AL (2015) cAMP-induced phosphorylation of $26 \mathrm{~S}$ proteasomes on Rpn6/PSMD11 enhances their activity and the degradation of misfolded proteins. Proc Natl Acad Sci USA 112:E7176-7185

Lowery DM, Clauser KR, Hjerrild M, Lim D, Alexander J, Kishi K, Ong SE, Gammeltoft S, Carr SA, Yaffe MB (2007) Proteomic screen defines the Polo-box domain interactome and identifies Rock2 as a Plk1 substrate. Embo J 26:2262-2273

Lu H, Zong C, Wang Y, Young GW, Deng N, Souda P, Li X, Whitelegge J, Drews O, Yang PY et al (2008) Revealing the dynamics of the $20 \mathrm{~S}$ proteasome phosphoproteome: a combined $\mathrm{CID}$ and electron transfer dissociation approach. Mol Cell Proteomics 7:2073-2089

Lu Y, Lee BH, King RW, Finley D, Kirschner MW (2015) Substrate degradation by the proteasome: a single-molecule kinetic analysis. Science 348:1250834

Ludemann R, Lerea KM, Etlinger JD (1993) Copurification of casein kinase II with $20 \mathrm{~S}$ proteasomes and phosphorylation of a $30-\mathrm{kDa}$ proteasome subunit. J Biol Chem 268:17413-17417

Lundby A, Andersen MN, Steffensen AB, Horn H, Kelstrup CD, Francavilla C, Jensen LJ, Schmitt N, Thomsen MB, Olsen JV (2013) In vivo phosphoproteomics analysis reveals the cardiac targets of beta-adrenergic receptor signaling. Sci Signal 6:rs11

Luo W, Slebos RJ, Hill S, Li M, Brabek J, Amanchy R, Chaerkady R, Pandey A, Ham AJ, Hanks SK (2008) Global impact of oncogenic Src on a phosphotyrosine proteome. J Proteome Res 7:34473460 
Manning G, Whyte DB, Martinez R, Hunter T, Sudarsanam S (2002) The protein kinase complement of the human genome. Science 298:1912-1934

Marambaud P, Wilk S, Checler F (1996) Protein kinase A phosphorylation of the proteasome: a contribution to the alpha-secretase pathway in human cells. J Neurochem 67:2616-2619

Mason GG, Hendil KB, Rivett AJ (1996) Phosphorylation of proteasomes in mammalian cells. Identification of two phosphorylated subunits and the effect of phosphorylation on activity. Eur J Biochem 238:453-462

Mason GG, Murray RZ, Pappin D, Rivett AJ (1998) Phosphorylation of ATPase subunits of the $26 \mathrm{~S}$ proteasome. FEBS Lett 430 : 269-274

Matsuoka S, Ballif BA, Smogorzewska A, McDonald ER 3rd, Hurov KE, Luo J, Bakalarski CE, Zhao Z, Solimini N, Lerenthal Y et al (2007) ATM and ATR substrate analysis reveals extensive protein networks responsive to DNA damage. Science 316:1160-1166

Matyskiela ME, Lander GC, Martin A (2013) Conformational switching of the $26 \mathrm{~S}$ proteasome enables substrate degradation. Nat Struct Mol Biol 20:781-788

Mayya V, Lundgren DH, Hwang SI, Rezaul K, Wu L, Eng JK, Rodionov V, Han DK (2009) Quantitative phosphoproteomic analysis of $\mathrm{T}$ cell receptor signaling reveals system-wide modulation of protein-protein interactions. Sci Signal 2:ra46

Mertins P, Yang F, Liu T, Mani DR, Petyuk VA, Gillette MA, Clauser KR, Qiao JW, Gritsenko MA, Moore RJ et al (2014) Ischemia in tumors induces early and sustained phosphorylation changes in stress kinase pathways but does not affect global protein levels. Mol Cell Proteomics 13:1690-1704

Moreno D, Knecht E, Viollet B, Sanz P (2008) A769662, a novel activator of AMP-activated protein kinase, inhibits non-proteolytic components of the $26 \mathrm{~S}$ proteasome by an AMPK-independent mechanism. FEBS Lett 582:2650-2654

Murata S, Sasaki K, Kishimoto T, Niwa S, Hayashi H, Takahama Y, Tanaka K (2007) Regulation of CD8+ T cell development by thymus-specific proteasomes. Science 316:1349-1353

Murata S, Yashiroda H, Tanaka K (2009) Molecular mechanisms of proteasome assembly. Nat Rev Mol Cell Biol 10:104-115

Murray PF, Pardo PS, Zelada AM, Passeron S (2002) In vivo and in vitro phosphorylation of Candida albicans $20 S$ proteasome. Arch Biochem Biophys 404:116-125

Myeku N, Wang H, Figueiredo-Pereira ME (2012) cAMP stimulates the ubiquitin/proteasome pathway in rat spinal cord neurons. Neurosci Lett 527:126-131

Myeku N, Clelland CL, Emrani S, Kukushkin NV, Yu WH, Goldberg AL, Duff KE (2016) Tau-driven 26S proteasome impairment and cognitive dysfunction can be prevented early in disease by activating CAMP-PKA signaling. Nat Med 22:46-53

Nagano K, Shinkawa T, Mutoh H, Kondoh O, Morimoto S, Inomata N, Ashihara M, Ishii N, Aoki Y, Haramura M (2009) Phosphoproteomic analysis of distinct tumor cell lines in response to nocodazole treatment. Proteomics 9:2861-2874

Olsen JV, Blagoev B, Gnad F, Macek B, Kumar C, Mortensen P, Mann M (2006) Global, in vivo, and site-specific phosphorylation dynamics in signaling networks. Cell 127:635-648

Olsen JV, Vermeulen M, Santamaria A, Kumar C, Miller ML, Jensen LJ, Gnad F, Cox J, Jensen TS, Nigg EA et al (2010) Quantitative phosphoproteomics reveals widespread full phosphorylation site occupancy during mitosis. Sci Signal 3:ra3

Pack CG, Yukii H, Toh-e A, Kudo T, Tsuchiya H, Kaiho A, Sakata E, Murata S, Yokosawa H, Sako Y et al (2014) Quantitative live-cell imaging reveals spatio-temporal dynamics and cytoplasmic assembly of the $26 \mathrm{~S}$ proteasome. Nat Commun 5:3396

Pan C, Olsen JV, Daub H, Mann M (2009) Global effects of kinase inhibitors on signaling networks revealed by quantitative phosphoproteomics. Mol Cell Proteomics 8:2796-2808

Pardo PS, Murray PF, Walz K, Franco L, Passeron S (1998) In vivo and in vitro phosphorylation of the alpha 7/PRS1 subunit of Saccharomyces cerevisiae $20 \mathrm{~S}$ proteasome: in vitro phosphorylation by protein kinase CK2 is absolutely dependent on polylysine. Arch Biochem Biophys 349:397-401

Park S, Roelofs J, Kim W, Robert J, Schmidt M, Gygi SP, Finley D (2009) Hexameric assembly of the proteasomal ATPases is templated through their $C$ termini. Nature 459:866-870

Pereira ME, Wilk S (1990) Phosphorylation of the multicatalytic proteinase complex from bovine pituitaries by a copurifying cAMP-dependent protein kinase. Arch Biochem Biophys 283:6874

Peth A, Kukushkin N, Bosse M, Goldberg AL (2013) Ubiquitinated proteins activate the proteasomal ATPases by binding to Usp14 or Uch37 homologs. J Biol Chem 288:7781-7790

Petrocca F, Altschuler G, Tan SM, Mendillo ML, Yan H, Jerry DJ, Kung AL, Hide W, Ince TA, Lieberman J (2013) A genome-wide siRNA screen identifies proteasome addiction as a vulnerability of basal-like triple-negative breast cancer cells. Cancer Cell 24:182-196

Rabl J, Smith DM, Yu Y, Chang SC, Goldberg AL, Cheng Y (2008) Mechanism of gate opening in the $20 \mathrm{~S}$ proteasome by the proteasomal ATPases. Mol Cell 30:360-368

Rainer PP, Kass DA (2016) Old dog, new tricks: novel cardiac targets and stress regulation by protein kinase $\mathrm{G}$. Cardiovasc Res 111:154-162

Ranek MJ, Terpstra EJ, Li J, Kass DA, Wang X (2013) Protein kinase $g$ positively regulates proteasome-mediated degradation of misfolded proteins. Circulation 128:365-376

Rigbolt KT, Prokhorova TA, Akimov V, Henningsen J, Johansen PT, Kratchmarova I, Kassem M, Mann M, Olsen JV, Blagoev B (2011) System-wide temporal characterization of the proteome and phosphoproteome of human embryonic stem cell differentiation. Sci Signal 4:rs3

Rikova K, Guo A, Zeng Q, Possemato A, Yu J, Haack H, Nardone J, Lee K, Reeves C, Li Y et al (2007) Global survey of phosphotyrosine signaling identifies oncogenic kinases in lung cancer. Cell 131:1190-1203

Rivett JA, Bose S, Brooks P, Broadfoot KI (2001) Regulation of proteasome complexes by $\mathrm{Y}$-interferon and phosphorylation. Biochimie 83:363-366

Roelofs J, Park S, Haas W, Tian G, McAllister FE, Huo Y, Lee BH, Zhang F, Shi Y, Gygi SP et al (2009) Chaperone-mediated pathway of proteasome regulatory particle assembly. Nature 459:861-865

Ruperez P, Gago-Martinez A, Burlingame AL, Oses-Prieto JA (2012) Quantitative phosphoproteomic analysis reveals a role for serine 
and threonine kinases in the cytoskeletal reorganization in early $T$ cell receptor activation in human primary $\mathrm{T}$ cells. Mol Cell Proteomics 11:171-186

Rush J, Moritz A, Lee KA, Guo A, Goss VL, Spek EJ, Zhang H, Zha XM, Polakiewicz RD, Comb MJ (2005) Immunoaffinity profiling of tyrosine phosphorylation in cancer cells. NatBiotechnol 23:94-101

Santamaria A, Wang B, Elowe S, Malik R, Zhang F, Bauer M, Schmidt A, Sillje HH, Korner R, Nigg EA (2011) The Plk1dependent phosphoproteome of the early mitotic spindle. Mol Cell Proteomics 10(M110):004457

Santarius T, Shipley J, Brewer D, Stratton MR, Cooper CS (2010) A census of amplified and overexpressed human cancer genes. Nat Rev Cancer 10:59-64

Satoh K, Nishikawa T, Yokosawa H, Sawada H (1995) Phosphorylation of proteasome substrate by a protein kinase associated with the $26 \mathrm{~S}$ proteasome is linked to the ATP-dependent proteolysis of the 26 S proteasome. Biochem Biophys Res Commun 213:7-14

Satoh K, Sasajima H, Nyoumura K-I, Yokosawa H, Sawada H (2000) Assembly of the $26 \mathrm{~S}$ proteasome is regulated by phosphorylation of the p45/Rpt6 ATPase subunit. Biochemistry 40:314-319

Schmidt M, Finley D (2014) Regulation of proteasome activity in health and disease. Biochim Biophys Acta 1843:13-25

Schmidt F, Dahlmann B, Hustoft HK, Koehler CJ, Strozynski M, Kloss A, Zimny-Arndt U, Jungblut PR, Thiede B (2011) Quantitative proteome analysis of the $20 \mathrm{~S}$ proteasome of apoptotic Jurkat T cells. Amino Acids 41:351-361

Schreiner P, Chen X, Husnjak K, Randles L, Zhang N, Elsasser S, Finley D, Dikic I, Walters KJ, Groll M (2008) Ubiquitin docking at the proteasome through a novel pleckstrin-homology domain interaction. Nature 453:548-552

Schweitzer A, Aufderheide A, Rudack T, Beck F, Pfeifer G, Plitzko JM, Sakata E, Schulten K, Forster F, Baumeister W (2016) Structure of the human $26 \mathrm{~S}$ proteasome at a resolution of $3.9 \mathrm{~A}$. Proc Natl Acad Sci USA 113:7816-7821

Scruggs SB, Zong NC, Wang D, Stefani E, Ping P (2012) Posttranslational modification of cardiac proteasomes: functional delineation enabled by proteomics. Am J Physiol Heart Circ Physiol 303:H9-18

Sha Z, Peth A, Goldberg AL (2011) Keeping proteasomes under control-a role for phosphorylation in the nucleus. Proc Natl Acad Sci USA 108:18573-18574

Sharma K, D'Souza RC, Tyanova S, Schaab C, Wisniewski JR, Cox J, Mann M (2014) Ultradeep human phosphoproteome reveals a distinct regulatory nature of Tyr and Ser/Thr-based signaling. Cell Rep 8:1583-1594

Shi Y, Chen X, Elsasser S, Stocks BB, Tian G, Lee BH, Shi Y, Zhang $\mathrm{N}$, de Poot SA, Tuebing $\mathrm{F}$ et al (2016) Rpn1 provides adjacent receptor sites for substrate binding and deubiquitination by the proteasome. Science. doi:10.1126/science.aad9421

Smith DM, Kafri G, Cheng Y, Ng D, Walz T, Goldberg AL (2005) ATP binding to PAN or the 26S ATPases causes association with the $20 \mathrm{~S}$ proteasome, gate opening, and translocation of unfolded proteins. Mol Cell 20:687-698

Smith DM, Chang SC, Park S, Finley D, Cheng Y, Goldberg AL (2007) Docking of the proteasomal ATPases' carboxyl termini in the $20 \mathrm{~S}$ proteasome's alpha ring opens the gate for substrate entry. Mol Cell 27:731-744
Stadtmueller BM, Hill CP (2011) Proteasome activators. Mol Cell 41:8-19

Stokes MP, Rush J, Macneill J, Ren JM, Sprott K, Nardone J, Yang V, Beausoleil SA, Gygi SP, Livingstone M et al (2007) Profiling of UV-induced ATM/ATR signaling pathways. Proc Natl Acad Sci USA 104:19855-19860

Taipale M, Krykbaeva I, Koeva M, Kayatekin C, Westover KD, Karras GI, Lindquist S (2012) Quantitative analysis of HSP90client interactions reveals principles of substrate recognition. Cell 150:987-1001

Tan CS, Pasculescu A, Lim WA, Pawson T, Bader GD, Linding R (2009) Positive selection of tyrosine loss in metazoan evolution. Science 325:1686-1688

Trost M, Sauvageau M, Herault O, Deleris P, Pomies C, Chagraoui J, Mayotte N, Meloche S, Sauvageau G, Thibault P (2012) Posttranslational regulation of self-renewal capacity: insights from proteome and phosphoproteome analyses of stem cell leukemia. Blood 120:e17-27

Tsai CF, Wang YT, Yen HY, Tsou CC, Ku WC, Lin PY, Chen HY, Nesvizhskii Al, Ishihama Y, Chen YJ (2015) Large-scale determination of absolute phosphorylation stoichiometries in human cells by motif-targeting quantitative proteomics. Nat Commun 6:6622

Uechi H, Hamazaki J, Murata S (2014) Characterization of the testisspecific proteasome subunit alpha4s in mammals. J Biol Chem 289:12365-12374

Um JW, Im E, Park J, Oh Y, Min B, Lee HJ, Yoon JB, Chung KC (2010) ASK1 negatively regulates the $26 \mathrm{~S}$ proteasome. J Biol Chem 285:36434-36446

Umeda M, Manabe Y, Uchimiya H (1997) Phosphorylation of the C2 subunit of the proteasome in rice (Oryza sativa L.). FEBS Lett 403:313-317

Unno M, Mizushima T, Morimoto Y, Tomisugi Y, Tanaka K, Yasuoka $\mathrm{N}$, Tsukihara $\mathrm{T}$ (2002) The structure of the mammalian $20 \mathrm{~S}$ proteasome at $2.75 \mathrm{~A}$ resolution. Structure 10:609-618

Unverdorben P, Beck F, Sledz P, Schweitzer A, Pfeifer G, Plitzko JM, Baumeister W, Forster F (2014) Deep classification of a large cryo-EM dataset defines the conformational landscape of the $26 \mathrm{~S}$ proteasome. Proc Natl Acad Sci USA 111:5544-5549

van de Weerdt BC, Medema RH (2006) Polo-like kinases: a team in control of the division. Cell Cycle 5:853-864

Verma R, Aravind L, Oania R, McDonald WH, Yates JR 3rd, Koonin EV, Deshaies RJ (2002) Role of Rpn11 metalloprotease in deubiquitination and degradation by the $26 \mathrm{~S}$ proteasome. Science 298:611-615

Viana R, Aguado C, Esteban I, Moreno D, Viollet B, Knecht E, Sanz $P(2008)$ Role of AMP-activated protein kinase in autophagy and proteasome function. Biochem Biophys Res Commun 369: 964-968

Wang X, Huang $L$ (2008) Identifying dynamic interactors of protein complexes by quantitative mass spectrometry. Mol Cell Proteomics 7:46-57

Wang X, Chen CF, Baker PR, Chen PL, Kaiser P, Huang L (2007) Mass spectrometric characterization of the affinity-purified human $26 S$ proteasome complex. Biochemistry 46:3553-3565

Wang S, Zhang M, Liang B, Xu J, Xie Z, Liu C, Viollet B, Yan D, Zou $\mathrm{MH}$ (2010) AMPKalpha2 deletion causes aberrant expression 
and activation of $\mathrm{NAD}(\mathrm{P}) \mathrm{H}$ oxidase and consequent endothelial dysfunction in vivo: role of $26 \mathrm{~S}$ proteasomes. Circ Res 106: 1117-1128

Wang R, Ferraris JD, Izumi Y, Dmitrieva N, Ramkissoon K, Wang G, Gucek M, Burg MB (2014) Global discovery of high-NaCl-induced changes of protein phosphorylation. Am J Physiol Cell Physiol 307:C442-454

Wani PS, Suppahia A, Capalla X, Ondracek A, Roelofs J (2016) Phosphorylation of the C-terminal tail of proteasome subunit alpha7 is required for binding of the proteasome quality control factor Ecm29. Sci Rep 6:27873

Waxman L, Fagan JM, Goldberg AL (1987) Demonstration of two distinct high molecular weight proteases in rabbit reticulocytes, one of which degrades ubiquitin conjugates. J Biol Chem 262:2451-2457

Weintz G, Olsen JV, Fruhauf K, Niedzielska M, Amit I, Jantsch J, Mages J, Frech C, Dolken L, Mann M et al (2010) The phosphoproteome of toll-like receptor-activated macrophages. Mol Syst Biol 6:371

Williams GR, Bethard JR, Berkaw MN, Nagel AK, Luttrell LM, Ball LE (2016) Exploring $G$ protein-coupled receptor signaling networks using SILAC-based phosphoproteomics. Methods 92:36-50

Worden EJ, Padovani C, Martin A (2014) Structure of the Rpn11Rpn8 dimer reveals mechanisms of substrate deubiquitination during proteasomal degradation. Nat Struct Mol Biol 21:220-227

Wu R, Haas W, Dephoure N, Huttlin EL, Zhai B, Sowa ME, Gygi SP (2011) A large-scale method to measure absolute protein phosphorylation stoichiometries. Nat Methods 8:677-683

Wu X, Tian L, Li J, Zhang Y, Han V, Li Y, Xu X, Li H, Chen X, Chen J et al (2012) Investigation of receptor interacting protein (RIP3)dependent protein phosphorylation by quantitative phosphoproteomics. Mol Cell Proteomics 11:1640-1651
Xu J, Wang AH, Oses-Prieto J, Makhijani K, Katsuno Y, Pei M, Yan L, Zheng YG, Burlingame A, Bruckner $K$ et al (2013) Arginine methylation initiates BMP-induced Smad signaling. Mol Cell 51:5-19

Yano M, Mori S, Kido H (1999) Intrinsic nucleoside diphosphate kinase-like activity is a novel function of the $20 \mathrm{~S}$ proteasome. J Biol Chem 274:34375-34382

Yao T, Cohen RE (2002) A cryptic protease couples deubiquitination and degradation by the proteasome. Nature 419:403-407

Yu Y, Smith DM, Kim HM, Rodriguez V, Goldberg AL, Cheng Y (2010) Interactions of PAN's C-termini with archaeal 20 S proteasome and implications for the eukaryotic proteasome-ATPase interactions. Embo J 29:692-702

Yuan F, Ma Y, You P, Lin W, Lu H, Yu Y, Wang X, Jiang J, Yang P, Ma $Q$ et al (2013) A novel role of proteasomal beta1 subunit in tumorigenesis. Biosci Rep 33:e0050

Zhang W, Wei Q (2011) Calcineurin stimulates the expression of inflammatory factors in RAW 264.7 cells by interacting with proteasome subunit alpha type 6. Biochem Biophys Res Commun 407:668-673

Zhang F, Hu Y, Huang P, Toleman CA, Paterson AJ, Kudlow JE (2007a) Proteasome function is regulated by cyclic AMP-dependent protein kinase through phosphorylation of Rpt6. J Biol Chem 282:22460-22471

Zhang F, Paterson AJ, Huang P, Wang K, Kudlow JE (2007b) Metabolic control of proteasome function. Physiology (Bethesda) 22:373-379

Zong C, Gomes AV, Drews O, Li X, Young GW, Berhane B, Qiao X, French SW, Bardag-Gorce F, Ping P (2006) Regulation of murine cardiac 20S proteasomes: role of associating partners. Circ Res 99:372-380 